\title{
Purification of Neural Precursor Cells Reveals the Presence of Distinct, Stimulus-Specific Subpopulations of Quiescent Precursors in the Adult Mouse Hippocampus
}

\author{
Dhanisha J. Jhaveri, Imogen 0’Keeffe, Gregory J. Robinson, @Qiong-Yi Zhao, Zong Hong Zhang, Virginia Nink, \\ Ramesh K. Narayanan, Geoffrey W. Osborne, Naomi R. Wray, and Perry F. Bartlett \\ The University of Queensland, Queensland Brain Institute, Brisbane 4072, Queensland, Australia
}

The activity of neural precursor cells in the adult hippocampus is regulated by various stimuli; however, whether these stimuli regulate the same or different precursor populations remains unknown. Here, we developed a novel cell-sorting protocol that allows the purification to homogeneity of neurosphere-forming neural precursors from the adult mouse hippocampus and examined the responsiveness of individual precursors to various stimuli using a clonal assay. We show that within the Hes5-GFP ${ }^{+} / \mathrm{Nestin}-\mathrm{GFP}^{+} / \mathrm{EGFR}^{+}$cell population, which comprises the majority of neurosphere-forming precursors, there are two distinct subpopulations of quiescent precursor cells, one directly activated by high- $\mathrm{KCl}$ depolarization, and the other activated by norepinephrine (NE). We then demonstrate that these two populations are differentially distributed along the septotemporal axis of the hippocampus, and show that the NE-responsive precursors are selectively regulated by GABA, whereas the KCl-responsive precursors are selectively modulated by corticosterone. Finally, based on RNAseq analysis by deep sequencing, we show that the progeny generated by activating NE-responsive versus KClresponsive quiescent precursors are molecularly different. These results demonstrate that the adult hippocampus contains phenotypically similar but stimulus-specific populations of quiescent precursors, which may give rise to neural progeny with different functional capacity.

Key words: adult neurogenesis; hippocampus; neural precursor cells; neural stem cells; norepinephrine; quiescent

\section{Introduction}

New neurons are generated from resident populations of stem and precursor cells in the adult mammalian hippocampus, and have been shown to play a pivotal role in spatial learning and memory, as well as in the regulation of mood (Santarelli et al., 2003; Saxe et al., 2006; Sahay and Hen, 2007; Deng et al., 2010; Snyder et al., 2011; Vukovic et al., 2013). The activity of these precursor cells is regulated by numerous factors, including physical exercise, stress, aging, neuronal activity, neurotransmitters, and antidepressants, thereby affecting the net production of new neurons (for review, see Ming and Song, 2005; Jhaveri et al., 2012). Recent studies have shown that, in addition to the active

\section{Received Feb. 5, 2015; revised March 30, 2015; accepted April 19, 2015.}

Author contributions: D.J.J., Q.-Y.Z., N.R.W., and P.F.B. designed research; D.J.J., I.O., G.J.R., V.N., and R.K.N. performed research; G.W.O. contributed unpublished reagents/analytic tools; D.J.J., Q.-Y.Z., Z.H.Z., N.R.W., and P.F.B. analyzed data; D.J.J. and P.F.B. wrote the paper.

This work was supported by a National Health and Medical Research Council Project Grant to D.J.J. and P.F.B., Australian Research Council Special Research Initiative in Stem Cells Science to P.F.B., and the Estate of Dr. Clem Jones A0. We thank Estella Newcombe, Boris Prosper, and Tim Butler for technical assistance; Queensland Brain Institute Centre for Brain Genomics for help with RNAseq; Dr. Robert Sullivan and Luke Hammond for help with histology and microscopy; and QBI Animal Facility staff for breeding and maintaining the animals used in this study. We especially thank Rowan Tweedale and Ashley Cooper for editorial assistance.

The authors declare no competing financial interests.

Correspondence should be addressed to either Dr. Dhanisha J. Jhaveri or Prof. Perry F. Bartlett, Queensland Brain Institute, The University of Queensland, Brisbane 4072, Queensland, Australia. E-mail: dhanisha@uq.edu.au or p.bartlett@uq.edu.au.

DOI:10.1523/JNEUROSCI.0504-15.2015

Copyright $\odot 2015$ the authors $\quad 0270-6474 / 15 / 358132-13 \$ 15.00 / 0$ precursor cells, the adult hippocampus also harbors a large population of quiescent stem and precursor cells, and have found that multiple mechanisms such as neuronal depolarization and longterm potentiation (Walker et al., 2008; Kameda et al., 2012), stimulation of $\beta 3$-adrenergic receptors (Jhaveri et al., 2010), GABA signaling antagonism (Song et al., 2012), and physical exercise (Lugert et al., 2010) act as potent activators of these cells. However, whether these different neurogenic stimuli regulate one homogenous population or different subpopulations of hippocampal precursor cells is currently unknown.

To date, the lack of unique, stem cell-specific markers has hindered the phenotypic and morphological identification of functional stem and precursor cells in the adult hippocampus. Generally, cells with radial glia-like (RGL) morphology residing in the subgranular zone (SGZ) of the dentate gyrus and expressing Nestin, Hes5, or GFAP are considered stem cells (Lugert et al., 2010; Bonaguidi et al., 2011). Within this population, the majority of cells $(>90 \%)$ are negative for proliferative markers such as Mcm2, Ki67, PCNA, or BrdU, and are often referred to as quiescent stem cells (Lugert et al., 2010; Encinas et al., 2011). Using these combined criteria, a genetic fate mapping study (Bonaguidi et al., 2011) conducted at a clonal resolution in vivo has shown differences in the self-renewal capacity and fate choice among Nestin ${ }^{+}$RGL cells, suggesting that the hippocampal stem cell population is not homogenous. Moreover, our previous studies have shown that neuronal depolarization and the monoamine 
neurotransmitter norepinephrine (NE) activate quiescent hippocampal precursor cells, including stem cells (Walker et al., 2008; Jhaveri et al., 2010), with combined NE and KCl treatment leading to activation of a much larger precursor pool (Jhaveri et al., 2010). Collectively, these studies have suggested that heterogeneous populations of quiescent precursor cells reside within the adult hippocampus. However, although reporter-based strategies, either alone (Gao et al., 2008; Jhaveri et al., 2010) or in combination with cell-surface markers (Walker et al., 2013), have been used to prospectively isolate and enrich adult hippocampal precursor cells, none have purified these cells to homogeneity, thereby failing to provide any direct evidence for the presence of phenotypically or functionally distinct populations of hippocampal precursor cells. In this study, we prospectively identify and isolate a pure population of hippocampal precursor cells and test whether different neurogenic stimuli lead to the activation of similar or distinct populations of quiescent precursors.

\section{Materials and Methods}

Animals. Adult (8- to 12 -week-old) C57BL/6J mice were used for the majority of the experiments conducted in this study. Mice expressing enhanced green fluorescent protein (GFP) under the control of the Hes5 promoter were obtained from the Mutant Mouse Regional Resource Center (University of Missouri, Columbia, MO). Nestin-GFP mice were bred on a C57BL/6J background, as previously described (Yu et al., 2005), and express GFP under the control of the Nestin promoter. Both of these lines allow visualization of endogenous populations of neural precursors in the adult hippocampus. All mice were housed in groups and were maintained on a $12 \mathrm{~h}$ light/dark cycle with ad libitum access to food and water. Animals were treated in accordance with the Australian Code of Practice for the Care and Use of Animals for Scientific Purposes, and ethics approval was obtained from the University of Queensland Animal Ethics Committee.

Adult hippocampal neurosphere cultures. Adult male C57BL/6J mice were killed by cervical dislocation, and their brains were removed in ice-cold Hank's essential medium. The hippocampi were microdissected from the overlying cortex, as previously described in detail (Jhaveri et al., 2010). The tissue was then minced, digested in $0.1 \%$ papain (Invitrogen), and gently triturated to obtain a single-cell suspension. An excess of DMEM/F-12 medium was added to halt enzymatic activity, and the cell suspension was centrifuged at 100 relative centrifugal force for $5 \mathrm{~min}$. The resulting pellet was resuspended in $1 \mathrm{ml}$ of complete neurosphere medium, composed of the following: NeuroCult NSC basal medium containing NeuroCult proliferation supplements (Stemcell Technologies), $2 \%$ bovine serum albumin (Invitrogen), $2 \mu \mathrm{g} / \mathrm{ml}$ heparin (SigmaAldrich), and growth factors including $20 \mathrm{ng} / \mathrm{ml}$ epidermal growth factor (EGF; receptor grade, BD Biosciences) and $10 \mathrm{ng} / \mathrm{ml}$ basic fibroblast growth factor (bFGF; recombinant bovine, Roche). The cells were then plated in a 96-well plate and cultured in complete neurosphere medium containing EGF and bFGF, in the presence or absence of L-(-)noradrenaline $(+)$-bitartrate salt monohydrate (i.e., NE; $10 \mu \mathrm{M}$ ), and 15 $\mathrm{mm} \mathrm{KCl}$ or NE plus $\mathrm{KCl}$. A water-soluble complex of corticosterone and 2 -hydroxypropyl $\beta$-cyclodextrin was used at $10 \mu \mathrm{M}$, and GABA was used at $50 \mu \mathrm{M}$ with or without $\mathrm{NE}$ or $\mathrm{KCl}$. Dopamine (DA) hydrochloride was used to investigate the effects of DA on hippocampal precursors. For the neurosphere inhibition assay, hippocampal cells were pretreated with or without $100 \mu \mathrm{M}$ NE or dansyl-conjugated DA, followed by washes with excess medium and replating in neurosphere medium containing either $10 \mu \mathrm{M}$ NE or $15 \mathrm{~mm} \mathrm{KCl}$.

To evaluate the anatomical distribution of NE- and KCl-responsive quiescent precursors along the septotemporal axis of the hippocampus, the isolated hippocampus was placed under the dissecting microscope. A graticule was placed beneath the plate, and each hippocampus was divided into three equal parts using a scalpel blade, as shown in Figure $4 A$. The septal, middle, and temporal regions of four hippocampi were pooled and processed for the neurosphere assay as described above.
Fluorescence-activated cell sorting. Brains from 7- to 9-week-old Hes5GFP mice (males) or Nestin-GFP mice (males and females) were removed, and their hippocampi were dissected as described above. A live-cell suspension was prepared using $0.1 \%$ papain, and the cells were resuspended in DMEM/F-12 medium. They were then incubated with biotinylated EGF conjugated with Alexa Fluor 647-streptavidin (EGF$647 ; 2 \mu \mathrm{g} / \mathrm{ml}$; Life Technologies) for $30-40 \mathrm{~min}$ at $4^{\circ} \mathrm{C}$, before being washed in an excess of DMEM/F-12 medium before sorting. Dead cells were excluded by labeling with propidium iodide $(1 \mu \mathrm{g} / \mathrm{ml})$. Cells were analyzed and sorted on a FACS Aria sorter (Becton Dickinson). The GFP-positive gate was set relative to the basal fluorescence levels obtained from wild-type littermates. The cells collected from each of the populations were plated in 96-well plates in complete neurosphere medium containing no additional factor (control), NE, KCl, or NE plus $\mathrm{KCl}$. Cells were imaged within $2 \mathrm{~h}$ of sorting using a Zeiss Axio-Imager microscope. The number of cells in each well (four to six wells for each sorted population) was quantified on the following day, and the average cell number for each sorted population was determined. For clonal analysis, sorted cells were diluted appropriately so as to obtain one cell per well. Clonal density was confirmed microscopically $\sim 16-18 \mathrm{~h}$ after plating by examining a minimum of eight wells for each of the fractions. A total of 24,32 , or 96 wells (depending on the total number of events obtained from the FACS for each experimental replicate) were treated per condition, and the total number of neurospheres obtained in each treatment group was determined on day 14. The total number of neurospheres obtained in the $\mathrm{NE}, \mathrm{KCl}$, and $\mathrm{NE}$ plus $\mathrm{KCl}$ groups was normalized to that obtained in the control group for each experimental replicate and plotted as a percentage of the control. The neurosphere-forming frequency was calculated by dividing the total number of single cells plated by the total number of neurospheres obtained for each of the treatment groups.

Immunohistochemistry. Eight-week-old Nestin-GFP mice $(n=2)$ were anesthetized with isoflurane and decapitated, and 400- $\mu \mathrm{m}$-thick coronal brain slices were prepared in an ice-cold oxygenated sucrose solution (87 mм NaCl, 25 mм NaHCO 3 , 25 mм glucose, 50 mм sucrose, $2.5 \mathrm{~mm} \mathrm{KCl}$, $1.2 \mathrm{mM} \mathrm{NaH}_{2} \mathrm{PO}_{4}, 4 \mathrm{~mm} \mathrm{MgCl}_{2}$, and $0.5 \mathrm{~mm} \mathrm{CaCl}_{2}$ ), using a Vibratome (Leica). Slices were then placed in oxygenated artificial CSF (aCSF; 118 $\mathrm{mm} \mathrm{NaCl}, 25 \mathrm{~mm} \mathrm{NaHCO}, 10 \mathrm{~mm}$ glucose, $2.5 \mathrm{~mm} \mathrm{KCl}, 1.2 \mathrm{~mm}$ $\mathrm{NaHPO}_{4}, 1.3 \mathrm{~mm} \mathrm{MgCl}$, and $2.5 \mathrm{mM} \mathrm{CaCl}_{2}$ ) and allowed to recover for $20 \mathrm{~min}$ at room temperature. To visualize EGF receptor (EGFR)expressing cells in the hippocampus, sections were incubated with fluorescently tagged EGF ligand (EGF-647) for $45 \mathrm{~min}$ at room temperature, before being washed with excess aCSF and fixed with ice-cold $4 \%$ paraformaldehyde. Slices were then washed in $0.1 \mathrm{~m}$ phosphate buffer, embedded in $2 \%$ agarose, and resectioned $(40 \mu \mathrm{m})$ using a vibratome. They were then blocked in PBS containing 0.1\% Triton X-100 (PBTX) and 5\% normal goat serum for $1 \mathrm{~h}$, followed by overnight incubation with chicken anti-GFP (1:4000; Life Technologies), after which they were washed three times using $0.1 \%$ PBTX and incubated for $2 \mathrm{~h}$ at room temperature with the secondary antibody goat anti-mouse Alexa Fluor 488 (1:2000; Life Technologies) and DAPI (1:1000). After several washes, the sections were mounted using Fluoromount (DakoCytomation) and imaged on a spinning-disk confocal system (Marianas; Intelligent Imaging Innovations) consisting of a Axio Observer Z1 (Carl Zeiss) equipped with a CSU-W1 spinning-disk head (Yokogawa Corporation of America), an ORCA-Flash4.0 version 2 sCMOS camera (Hamamatsu Photonics), and $20 \times 0.8$ numerical aperture (NA) PlanApo and $40 \times 1.2 \mathrm{NA}$ $\mathrm{C}$-Apo objectives. Image acquisition was performed using SlideBook version 6.0 (3i). The resulting images were processed and visualized using Imaris version 7.7 software (Bitplane). Nestin-GFP ${ }^{+} / \mathrm{EGFR}^{+}$doublelabeled cells were quantified from five sections per mouse through the rostrocaudal axis of the dentate gyrus and were classified as RGL (DAPIpositive cell body in the SGZ with a radial-like process extending into the granule cell layer) or non-RGL (DAPI-positive cell body in the SGZ with no process). The total number of Nestin-GFP ${ }^{+}$cells per dentate gyrus was quantified using the Imaris surface generation tools.

Corticosterone treatment. An emulsion of corticosterone was prepared by mixing corticosterone with $10 \%$ DMSO in sesame oil. Mice received a single subcutaneous injection of corticosterone $(n=8,40 \mathrm{mg} / \mathrm{kg} / \mathrm{d})$ or vehicle ( $n=5,10 \%$ DMSO in sesame oil) on each of 7 consecutive days. 
This dose of corticosterone has been shown to elevate levels of circulating corticosterone, induce depressive-like behaviors, and reduce hippocampal neurogenesis (Johnson et al., 2006; Wong and Herbert, 2006; Murray et al., 2008; Brummelte and Galea, 2010).

Transcriptome profiling by RNA sequencing and microarray analysis. Primary neurospheres measuring $>200 \mu \mathrm{m}$ in diameter were collected for each of the individual treatments ( $\mathrm{NE}$ or $\mathrm{KCl}$ ). Each biological replicate comprised large neurospheres generated from eight hippocampi. Total RNA was extracted from neurospheres using TRIzol Reagent (Life Technologies) and chloroform (Sigma-Aldrich), followed by precipitation and washing with isopropanol and ethanol. Total RNA samples were treated with the Ambion DNA-free kit according to the manufacturer instructions to remove any contamination from genomic DNA (Life Technologies). DNase-treated samples were assessed for their RNA integrity number (RIN) using an Agilent RNA 6000 Pico Kit (Agilent Technologies) on the Agilent 2100 Bioanalyzer according to the manufacturer instructions. RNA samples with a RIN of $>9$ were selected, and a total of $100 \mathrm{ng}$ was used for sequencing each sample ( $n=4$ biological replicates). Sequence libraries were generated using the Illumina TrueSeq Prep kit (Illumina) as per the manufacturer instructions. An 8 pm final concentration of each library was used for subsequent cluster generation using a version 3 flow cell. The Illumina HiSeq 2000 sequencing system was used for paired-end sequencing with a read length of $101 \mathrm{bp}$. Image processing and sequence extraction were achieved using the standard Illumina HiSeq 2000 software and pipelines that were developed in house. The RNA sequencing dataset of this study has been deposited in the NCBI Sequence Read Archive with accession ID SRX810866.

Microarray data for the NE- and $\mathrm{KCl}$-derived large neurospheres were generated essentially as described by Zhang et al. (2014) using Affymetrix GeneChip Mouse Gene 1.0 ST arrays (one new biological sample and two biological replicates in common with the RNA sequencing data). The original microarray data (.CEL files) were transferred to the Partek Genomics Suite, and data analysis was performed as described by Narayanan et al. (2013). The results of microarray data served as an independent validation for differentially expressed genes that were detected from the RNA sequencing analysis. The microarray data from this study have been deposited in the NCBI Gene Expression Omnibus with accession ID GSE67304.

Bioinformatics. CASAVA software (version 1.8.2) was used to demultiplex the samples and generate the raw reads in fastq format, and the quality of raw sequence reads was evaluated using fastQC (version 0.10.1 devel) software. Low-quality nucleotides in the last 26 cycles were trimmed by custom PERL scripts before alignment. TopHat (version 1.3.2; Trapnell et al., 2009) was used to align the Illumina reads to the mouse reference genome (mm10) with the "-G mm10.GTF" option to provide gene model annotations. The FPKM (fragments per kilobase of exon per million fragments mapped) values of the genes were parsed from the outcome of Cufflinks (version 2.0.2; Trapnell et al., 2010) for the quantification of gene expression level. Based on "BAM" files with alignment results generated by TopHat and the gene transfer format (GTF) file with genomic features, HTSeq (version 0.5.3p9; Huang and Herbert, 2006) was used to generate read counts for each gene feature. Cuffdiff2 of the Cufflinks suite DESeq (version 1.10.1; Anders and $\mathrm{Hu}-$ ber, 2010) and edgeR (version 3.0.8; Robinson et al., 2010) were then used separately to identify the differentially expressed $(\mathrm{DE})$ genes at $5 \%$ false discovery rate (FDR) between the $\mathrm{KCl}$ and $\mathrm{NE}$ treatments for large neurospheres. The intersecting DE genes generated from these tools were compared and validated by the Affymetrix microarray platform using custom PERL scripts. Gene ontology (GO) enrichment analysis was conducted using DAVID tools (Huang et al., 2009) to identify the overrepresentation of GO terms in $433 \mathrm{DE}$ genes.

Statistical analysis. All values are expressed as the mean \pm SEM. Results were subjected to statistical analysis using the statistical software Prism (GraphPad) and analyzed using either Student's $t$ test or one-way or two-way ANOVA, with Bonferroni's post hoc test, as appropriate. Significance was determined at $p<0.05$.

\section{Results}

Quiescent hippocampal precursor cells activated by different stimuli are Hes5-GFP ${ }^{+}$and Nestin-GFP ${ }^{+}$

Our previous studies (Walker et al., 2008; Jhaveri et al., 2010) have shown that the treatment of adult hippocampal cells with either depolarizing levels of $\mathrm{KCl}$ or the neurotransmitter $\mathrm{NE} \mathrm{ac-}$ tivates quiescent precursor cells, resulting in a significant increase in the number of neurospheres, with an additive effect observed when the treatments are combined (Fig. 1A). This suggests that the adult hippocampus may harbor distinct populations of quiescent precursor cells that differ in their responsiveness to different stimuli. To determine the phenotypic identity of these cells, we used transgenic mice expressing GFP driven by Hes5 and Nestin promoters, respectively. Recent studies (Lugert et al., 2010; Encinas et al., 2011) have shown that a large proportion of Hes5-GFP ${ }^{+}$and Nestin-GFP ${ }^{+}$RGL cells in the SGZ are nondividing. Upon activation, these quiescent precursor cells show differences in their cell division dynamics and lineage potential (Bonaguidi et al., 2011, Lugert et al., 2012), although it remains unclear whether they are selectively activated by one or more neurogenic stimuli. We therefore used fluorescence-activated cell sorting to isolate Hes5- and Nestin-expressing hippocampal cells, and examined whether $\mathrm{NE}$ and $\mathrm{KCl}$ activated either or both of these populations in the neurosphere assay (Fig. 1B).

First, Hes5-GFP ${ }^{+}$and Hes5-GFP ${ }^{-}$cells were isolated from the adult hippocampus (Fig. 1C), and the cells were plated in control medium containing mitogens (EGF and bFGF), or were treated with $\mathrm{NE}, \mathrm{KCl}$, or $\mathrm{NE}$ and $\mathrm{KCl}$ in the presence of these mitogens. The Hes5-GFP ${ }^{+}$population contained all neurosphere-forming precursor cells, both active and quiescent, with no neurospheres observed in the Hes5-GFP ${ }^{-}$fraction in any of the treatment conditions. Treatment of the Hes5-GFP ${ }^{+}$cells with either $\mathrm{NE}$ or $\mathrm{KCl}$ alone led to a significant increase in the number of neurospheres, with combined $\mathrm{NE}$ and $\mathrm{KCl}$ treatment further increasing the total number of neurospheres (Fig. 1E). We also quantified the number of large neurospheres (measuring $>200 \mu \mathrm{m}$ in diameter) obtained in all conditions, as these have previously been shown to result from the activation of a multipotential quiescent stem cell population with self-renewing and extensive proliferative capacity (Walker et al., 2008, Jhaveri et al., 2010). NE or $\mathrm{KCl}$ treatment generated more large neurospheres per hippocampus than observed under control conditions (control, $0.5 \pm 0.3$ neurospheres; NE, $7.9 \pm 1.6$ neurospheres; $\mathrm{KCl}$, $3.1 \pm 0.5$ neurospheres), with a further significant increase obtained in $\mathrm{NE}$ and $\mathrm{KCl}(19.5 \pm 2.0$ neurospheres $)$ compared with $\mathrm{NE}$ or $\mathrm{KCl}$ alone ( $n=4$ experiments; $p<0.001$, unpaired $t$ test). These data suggest that both $\mathrm{NE}$ - and $\mathrm{KCl}$-responsive quiescent precursor cells, including a small population of highly proliferative stem cells, are Hes5-GFP ${ }^{+}$.

We then conducted a similar analysis using Nestin-GFP mice (Fig. $1 D, F)$. In contrast to the Hes5-GFP ${ }^{+}$fraction, which contained the entire precursor cell population, $75.6 \pm 5.0 \%$ of the total neurosphere activity was obtained in the Nestin-GFP ${ }^{+}$frac- $^{-}$ tion in control conditions ( $n=4$ experiments). Similar to Hes5$\mathrm{GFP}^{+}$cells, treatment of Nestin-GFP ${ }^{+}$cells with either NE or $\mathrm{KCl}$ led to a significant increase in neurosphere formation, with an additive effect observed in response to $\mathrm{NE}$ and $\mathrm{KCl}$ (Fig. $1 F$ ). Significantly more large neurospheres were also obtained in NE and $\mathrm{KCl}$ compared with $\mathrm{NE}$ or $\mathrm{KCl}$ alone for the Nestin-GFP ${ }^{+}$ fraction (control, $0.8 \pm 0.6$ neurospheres; NE, $10.8 \pm 3.6$ neurospheres; $\mathrm{KCl}, 13.8 \pm 1.9$ neurospheres; $\mathrm{NE}$ and $\mathrm{KCl}, 26.0 \pm 3.0$ neurospheres; $p<0.05$, unpaired $t$ test). Together, our results 


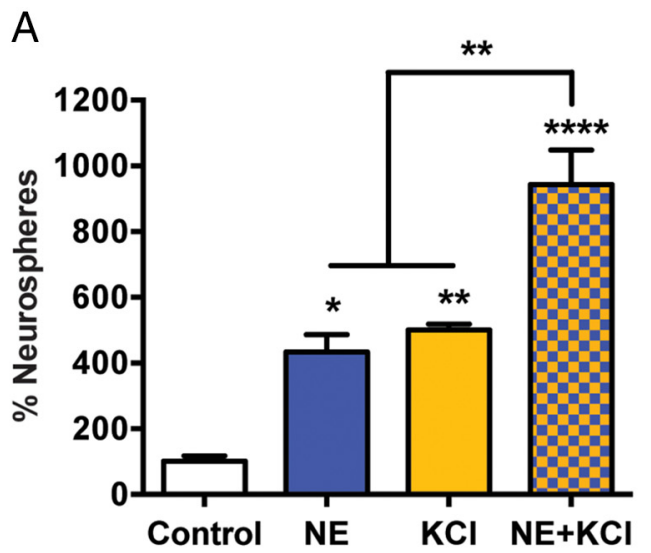

C
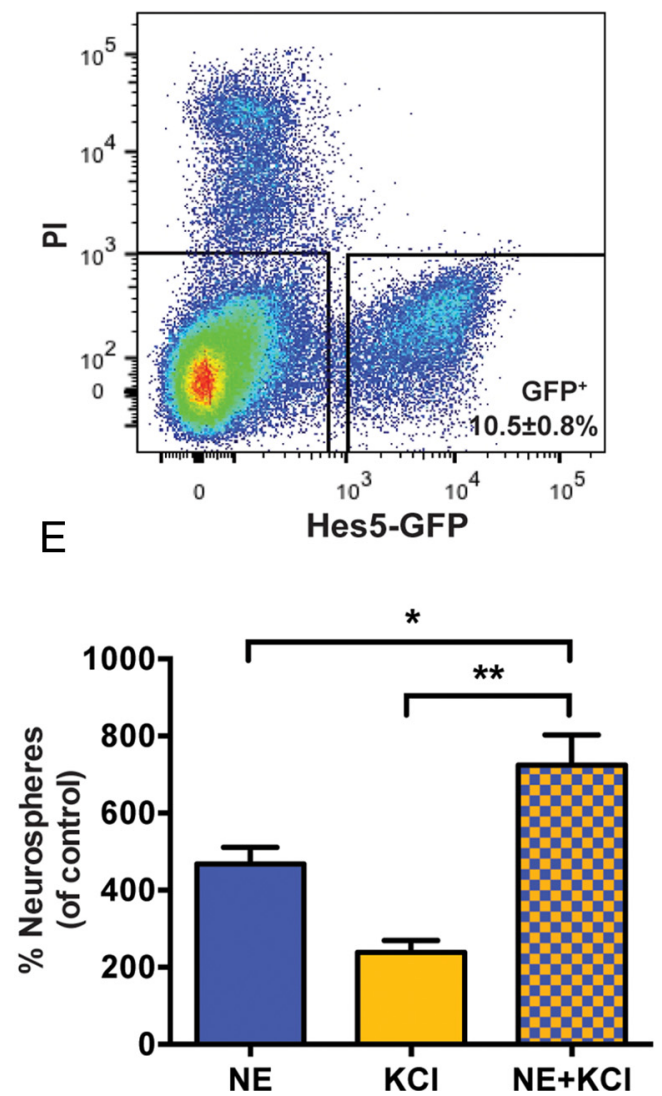

B
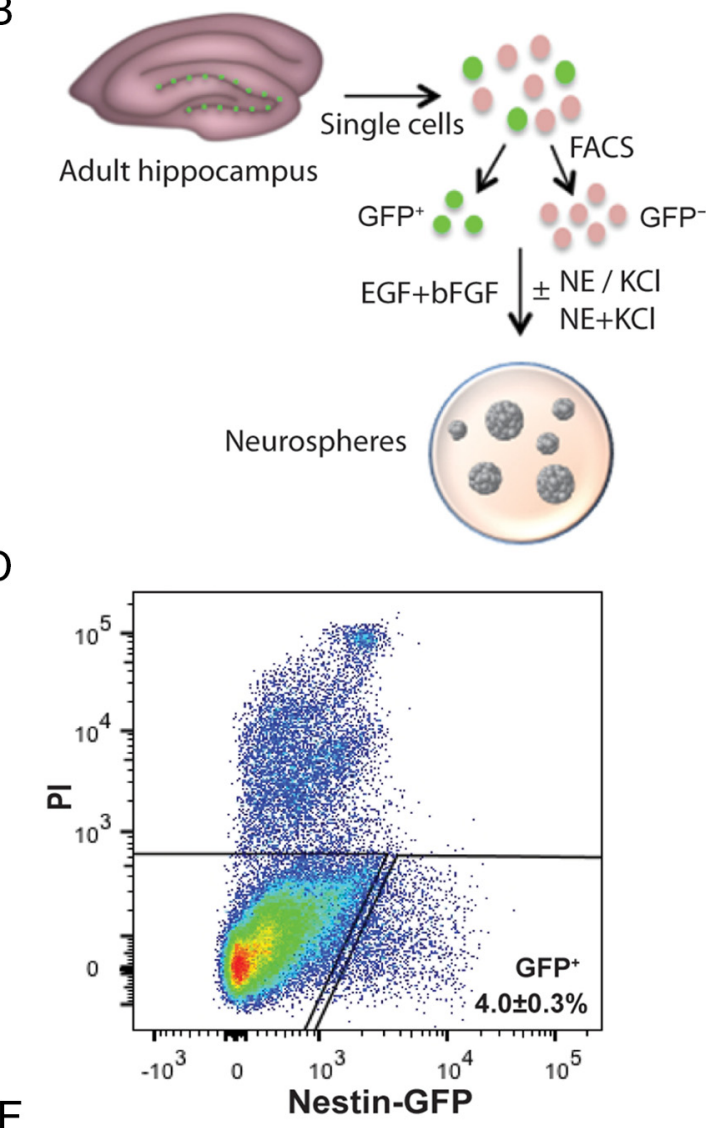

F

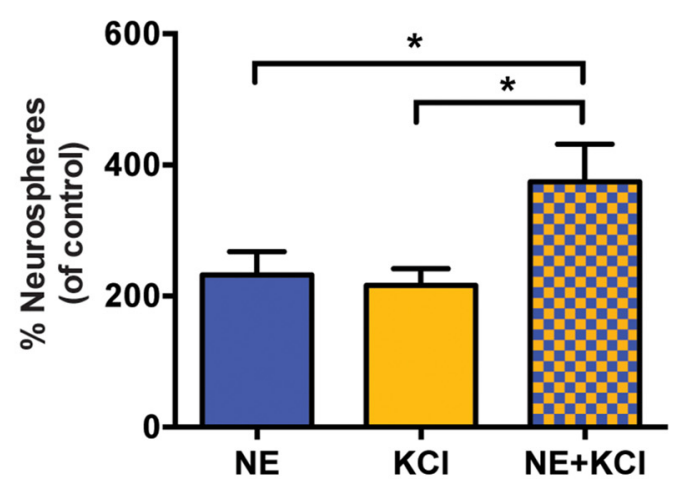

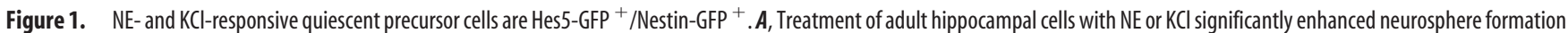
compared with that in control medium. Note that the combined treatment with $\mathrm{NE}$ and $\mathrm{KCl}$ resulted in a further increase in the number of neurospheres compared with either NE or $\mathrm{KCl}$ treatment alone ( $n=3$ experiments; one-way ANOVA: $F_{(3,8)}=33.32, p<0.0001$ ). $\boldsymbol{B}$, Schematic showing the experimental design for the isolation of GFP ${ }^{+}$and GFP ${ }^{-}$cells from the hippocampus of transgenic mice using fluorescence-activated cell sorting (FACS) and assaying their proliferative capacity using the neurosphere assay. $\boldsymbol{C}, \boldsymbol{D}$, Representative $F A C S$ plots showing gating of GFP ${ }^{+}$and $\mathrm{GFP}^{-}$cells from the hippocampi of Hes5-GFP (C) and Nestin-GFP (D) mice. Dead cells were excluded based on propidium iodide (PI) staining. $\boldsymbol{E}$, In the Hes5-GFP ${ }^{+}$fraction, the combined treatment with NE and $\mathrm{KCl}$ generated significantly more neurospheres compared with NE or KCl treatment alone ( $n=4$ experiments; unpaired $t$ test). $\boldsymbol{F}$, Similarly, in the Nestin-GFP + fraction, a $>2$-fold increase in neurosphere formation was seen in the NE and $\mathrm{KCl}$ conditions compared with the control, with a further increase observed in response to $\mathrm{NE}$ and $\mathrm{KCl}$ ( $n=4$ experiments; unpaired $t$ test). All values are represented as the mean \pm SEM: ${ }^{*} p<0.05,{ }^{* *} p<0.01,{ }^{* * * *} p<0.0001$.

demonstrate that both NE- and KCl-responsive quiescent precursor cells are Hes5-GFP ${ }^{+}$and Nestin-GFP ${ }^{+}$.

\section{Selection of Hes5-GFP ${ }^{+} / \mathrm{EGFR}^{+}$or Nestin-GFP ${ }^{+} / \mathrm{EGFR}^{+}$} cells purifies hippocampal precursors and reveals the presence of distinct subpopulations of quiescent cells in a clonal assay

We next sought to determine whether the increased number of neurospheres observed in $\mathrm{NE}$ and $\mathrm{KCl}$ was due to the additive effects of directly activating two distinct populations: the NE- and $\mathrm{KCl}$-responsive quiescent precursors. To demonstrate this unequivocally, it was necessary to conduct these experiments at a "true" clonal density of one cell per well. However, as only 1 in $86.9 \pm 23.2 \mathrm{Hes}$-GFP ${ }^{+}$cells $(n=4$ experiments $)$ and 1 in $67.5 \pm$ 9.0 Nestin-GFP ${ }^{+}$cells $(n=4$ experiments) formed a neurosphere in control medium, we first sought to enrich the neurosphere-forming precursors for this analysis. Given that selection based on the expression of EGFR has been used success- 
fully to prospectively identify and isolate neurosphere-forming precursor cells from the adult subventricular zone (SVZ; Pastrana et al., 2009; Codega et al., 2014), we examined whether concomitant selection of Hes5-GFP ${ }^{+} / \mathrm{EGFR}^{+}$or Nestin-GFP ${ }^{+} /$ $\mathrm{EGFR}^{+}$cells would further enrich hippocampal precursor cells. Using a fluorescently tagged EGF ligand (EGF-647), Hes5$\mathrm{GFP}^{+} / \mathrm{EGFR}^{+}$(Fig. $2 A, C$ ) and Nestin-GFP ${ }^{+} / \mathrm{EGFR}^{+}$(Fig. 2B) cells were isolated from the adult hippocampus and plated at a clonal density in a 96-well plate. Treatment of these cells with NE or $\mathrm{KCl}$ led to an increase in the number of neurospheres compared with the control condition (Fig. 2D,E), thereby demonstrating that both $\mathrm{NE}$ and $\mathrm{KCl}$ directly activate quiescent hippocampal precursor cells. More importantly, a further significant increase comparable to an additive effect was observed in the presence of NE and $\mathrm{KCl}$ in both the Hes5-GFP ${ }^{+} / \mathrm{EGFR}^{+}$(Fig. $2 D$ ) and Nestin-GFP ${ }^{+} / \mathrm{EGFR}^{+}$(Fig. $2 E$ ) populations compared with either treatment alone, thus providing further strong evidence that two distinct populations of quiescent precursors, those activated by $\mathrm{NE}$ and those activated by $\mathrm{KCl}$, are present in the adult hippocampus.

Notably, selection based on EGFR expression led to a very significant enrichment, with Hes5-GFP ${ }^{+} / \mathrm{EGFR}^{+}$cells representing a near-pure population of hippocampal precursor cells (Fig. $2 G$ ). One neurosphere was obtained for every $1.3 \pm 0.4$ Hes5-GFP ${ }^{+} / \mathrm{EGFR}^{+}$cells in response to $\mathrm{NE}$ and $\mathrm{KCl}$, which corresponds to $>75 \%$ of the purified cells being neurosphereforming precursors. A similar enrichment was also observed for Nestin-GFP ${ }^{+} / \mathrm{EGFR}^{+}$cells, with 1 in $2.3 \pm 0.6$ cells forming a neurosphere in $\mathrm{NE}$ and $\mathrm{KCl}$ (Fig. 2G). Overall, the majority of $\mathrm{NE}$ - and $\mathrm{KCl}$-responsive quiescent precursors were found to be Hes5-GFP ${ }^{+} / \mathrm{EGFR}^{+}$or Nestin-GFP ${ }^{+} / \mathrm{EGFR}^{+}($Fig. $2 \mathrm{H}, \mathrm{I}$ ).

We next investigated where in the adult hippocampus the $\mathrm{NE}$ - and $\mathrm{KCl}$-responsive precursors were located. Having demonstrated that both Hes5-GFP ${ }^{+} / \mathrm{EGFR}^{+}$and Nestin-GFP ${ }^{+} /$ $\mathrm{EGFR}^{+}$selection provided similar enrichment of the neurosphere-forming precursors, we conducted this analysis using Nestin-GFP mice. Flow cytometry-based analysis revealed that the entire population of Nestin-GFP ${ }^{+} / \mathrm{EGFR}^{+}$precursor cells $(231.5 \pm 40.8$ double-positive cells/brain) was contained within the dentate gyrus, constituting only $4.7 \pm 1.0 \%$ of the total Nestin-GFP ${ }^{+}$cells (Fig. $2 F$ ). Furthermore, to quantify and visualize the morphology of these neurosphere-forming precursors in situ, coronal hippocampal slices from Nestin-GFP mice were immunostained for EGFR using the EGF-647 ligand. Consistent with our flow cytometry data, this immunohistochemical analysis confirmed that Nestin-GFP ${ }^{+} / \mathrm{EGFR}^{+}$cells were rare, constituting $3.5 \pm 0.4 \%$ of the total Nestin-GFP ${ }^{+}$cells in the dentate gyrus. Importantly, these colabeled cells were present in the SGZ, with $32.6 \pm 7.9 \%$ of Nestin-GFP ${ }^{+} / \mathrm{EGFR}^{+}$cells exhibiting an RGL morphology (Fig. 2J,K,M) and $67.4 \pm 7.9 \%$ having a nonRGL morphology (Fig. $2 L, M$ ). Punctate EGFR expression was also noted on the processes of Nestin-GFP-expressing RGL cells (Fig. $2 J, K$ ). These findings indicate that both RGL and non-RGL precursors residing in the dentate gyrus are capable of forming neurospheres.

Together, these results demonstrate that Hes5-GFP ${ }^{+} /$Nestin$\mathrm{GFP}^{+} / \mathrm{EGFR}^{+}$cells represent a near-pure and predominantly neurosphere-forming precursor cell population in the adult dentate gyrus, and reveal that this population comprises two distinct subpopulations of quiescent precursors that are directly activated by either $\mathrm{NE}$ or $\mathrm{KCl}$.

\section{Inhibition of NE-responsive precursors does not affect KCl- responsive quiescent precursor cells}

To further confirm the existence of two distinct populations of quiescent precursor cells, we tested whether we could selectively inhibit one population without affecting the activity of the other. As we have previously shown that the stimulation of $\beta 3$ adrenergic receptors mediates NE-dependent activation of precursor cells (Jhaveri et al., 2010), a single-cell suspension of hippocampal cells was treated with the selective $\beta 3$ adrenergic receptor antagonist SR59230A in the presence of either NE or KCl. Treatment with SR59230A (50 nM) completely blocked the NEmediated increase in the number of neurospheres, but produced no change in the number of neurospheres obtained in the presence of $\mathrm{KCl}$ (Fig. 3A). In addition, we examined whether $100 \mu \mathrm{M}$ $\mathrm{NE}$, which we have found to inhibit neurosphere formation (data not shown), also selectively affects the activation of one or both populations of quiescent precursors. To test this, we treated freshly isolated hippocampal cells with $100 \mu \mathrm{M} \mathrm{NE}$ for $2.5 \mathrm{~h}$, after which the cells were washed and replated in neurosphere medium containing either $\mathrm{NE}$ or $\mathrm{KCl}$ (Fig. 3B). Pretreatment with high NE led to a significant reduction $(43 \pm 10.1 \%)$ in the number of NE-activated neurospheres, whereas the number of $\mathrm{KCl}$ activated neurospheres remained unchanged when compared with the control (no pretreatment) condition (Fig. 3C). Collectively, these results demonstrate that the mechanisms that lead to activation of these two distinct quiescent precursor populations are different, and show that inhibiting NE-responsive quiescent precursors does not affect the activity of the $\mathrm{KCl}$ responsive population.

In our efforts to identify additional factors that can activate quiescent hippocampal precursor cells, we have found that treatment with $10 \mu \mathrm{M}$ DA also results in a significant increase in neurosphere numbers, similar to the increases seen in the presence of $\mathrm{NE}$ and $\mathrm{KCl}$ (Fig. 3D,E). We therefore sought to determine whether combined treatment with DA would exert any additive effect. Although treatment with DA and NE produced no such effect (Fig. 3D), treatment with DA and $\mathrm{KCl}$ led to a significant increase in the total number of neurospheres (Fig. 3E). These results suggest that DA could be activating the same subpopulation of quiescent precursor cells as that activated by NE. To confirm this, we assessed neurosphere formation in the purified Nestin-GFP ${ }^{+}$cells at a clonal density. Similar to our results obtained from unsorted populations, no further increase in the number of neurospheres was obtained in DA and NE when compared with either treatment alone (neurosphere-forming frequency: DA, 1 in $29.2 \pm 0.6$; NE, 1 in $24.3 \pm 2.0$; DA and $\mathrm{NE}, 1$ in $27.8 \pm 7.2 ; n=2 ; p=0.6)$. Having established that DA directly activated the same population of precursors as that which was responsive to NE, we assessed whether a high dose of DA, which also significantly reduced neurosphere formation (data not shown), would selectively reduce the number of NE- but not KCl-activated neurospheres. Similar to our results obtained with high NE, pretreatment with a high DA dose also led to a significant reduction $(46.9 \pm 10.0 \%)$ in $\mathrm{NE}$-activated neurospheres but did not alter the number of $\mathrm{KCl}$-activated neurospheres (Fig. $3 F$ ). These data provide further evidence that the activity of a distinct subpopulation of quiescent precursors can be selectively attenuated, and reveal DA as another potent stimulus for the activation of the same subpopulation of quiescent hippocampal precursor cells as that which is responsive to NE. 
A

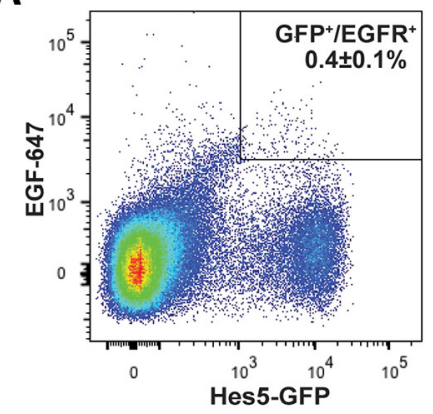

D

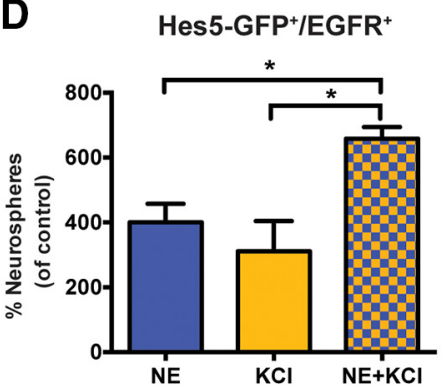

B

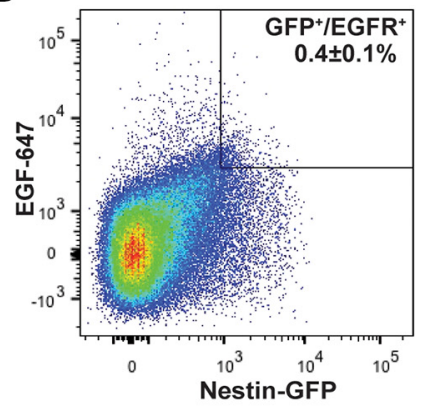

E

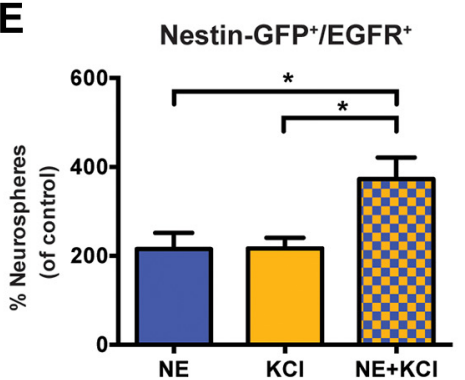

C

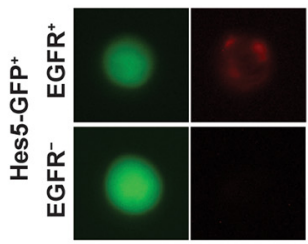

F

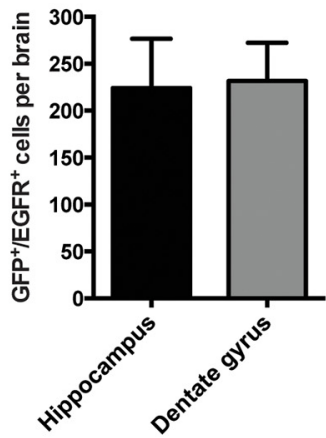

G Neurosphere-forming frequency

\begin{tabular}{|c|c|c|c|c|}
\hline & Control & $\mathrm{NE}$ & $\mathrm{KCl}$ & $\mathrm{NE}+\mathrm{KCl}$ \\
\hline $\begin{array}{c}\text { Hes5-GFP }^{+} \text {I } \\
\text { EGFR }^{+}\end{array}$ & $8.6 \pm 2.2$ & $2.1 \pm 0.3$ & $3.4 \pm 1.1$ & $1.3 \pm 0.4$ \\
\hline $\begin{array}{c}\text { Nestin-GFP }^{+} / \\
\text {EGFR }^{+}\end{array}$ & $9.8 \pm 3.5$ & $4.7 \pm 1.4$ & $4.9 \pm 2.2$ & $2.3 \pm 0.6$ \\
\hline
\end{tabular}

H Neurospheres in Hes5-GFP+/EGFR ${ }^{+}$
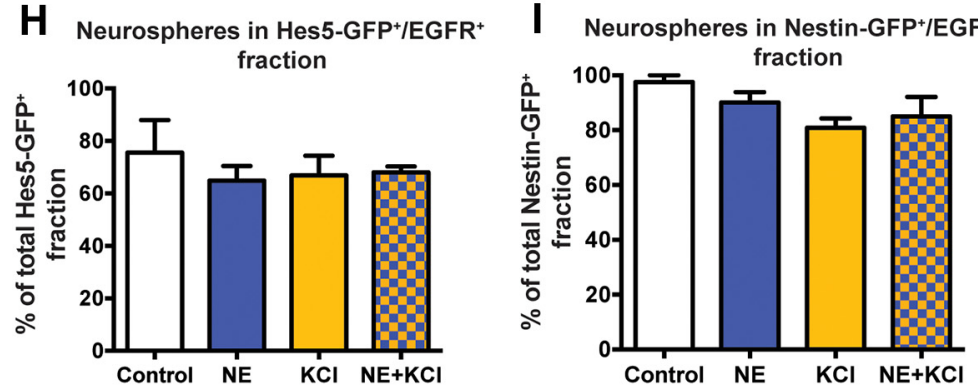

J

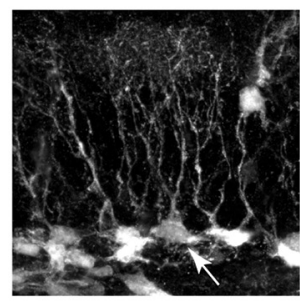

$\mathbf{L}$

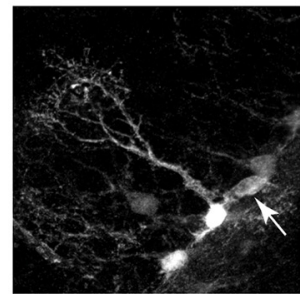

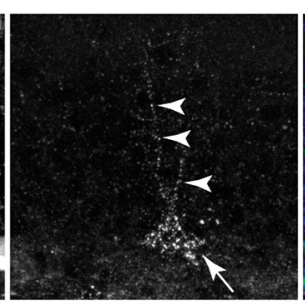

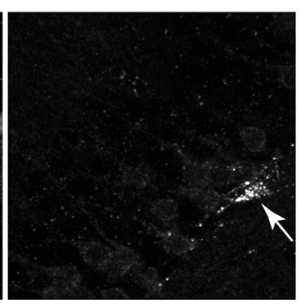

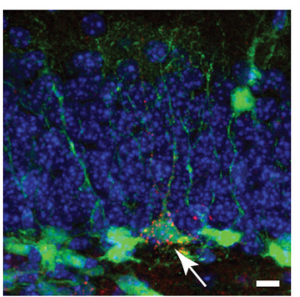

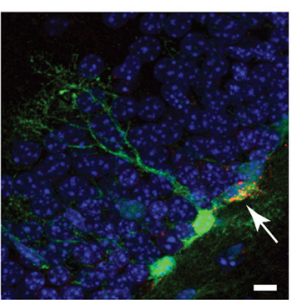

Nestin-GFP EGFR DAPI
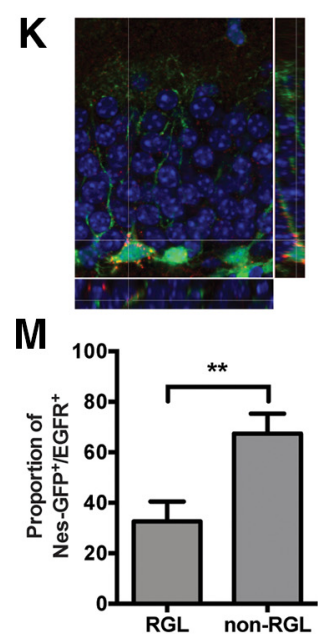

Figure 2. Identification and prospective purification of NE- and KCl-responsive quiescent precursor cells based on EGFR expression. $A, B$, FACS plots showing the gating strategy for selecting Hes5-GFP ${ }^{+} /$EGFR $^{+}$cells $(\boldsymbol{A})$ and Nestin-GFP ${ }^{+} /$EGFR $^{+}$cells $(\boldsymbol{B})$ from the total population of GFP ${ }^{+}$cells. C, Example of a FACS-isolated, live Hes5-GFP ${ }^{+} /$EGFR $^{+}$cell showing native GFP expression (green) and surface labeling of EGF-647 (red, top) compared with an Hes5-GFP ${ }^{+} /$EGFR $^{-}$cell (bottom). D, E, Hes5-GFP ${ }^{+} /$EGFR $^{+}$cells (D) and Nestin-GFP ${ }^{+} /$EGFR $^{+}$cells $(\boldsymbol{E})$ plated at a clonal density of 1 cell per well show an increase in neurosphere formation in the presence of $\mathrm{NE}$ or $\mathrm{KCl}$, with combined treatment producing a further increase compared with (Figure legend continues.) 
A

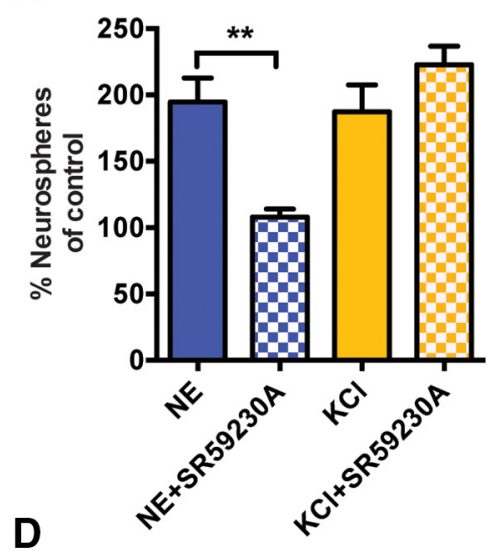

D

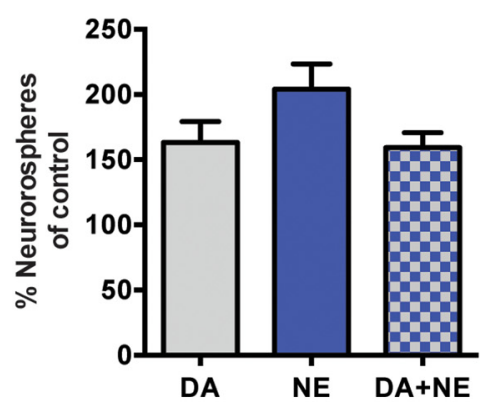

B

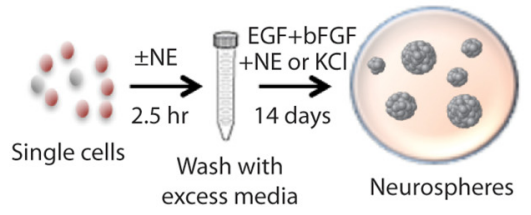

$\mathbf{E}$

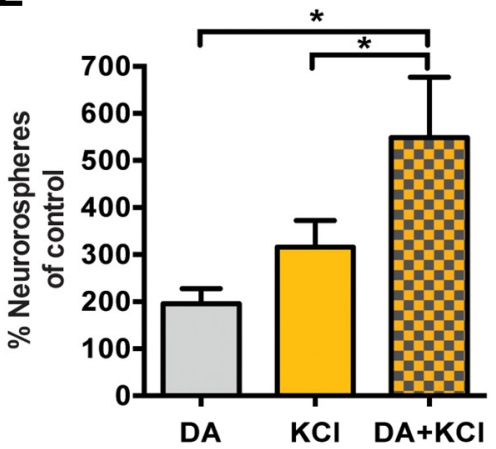

C

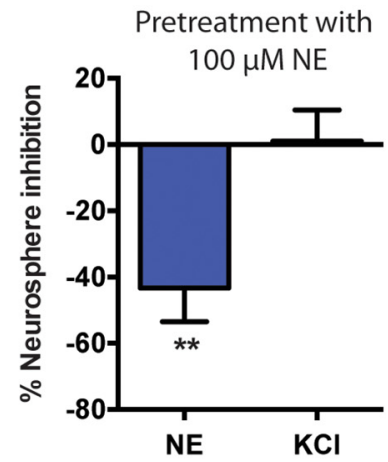

Figure 3. Inhibiting NE-responsive precursors does not affect the activity of KCl-activated quiescent precursor cells. A, Treatment with a selective $\beta 3$-adrenergic receptor blocker SR59230A (50 $\mathrm{nm}$ ) completely inhibited the NE-mediated increase in neurospheres but did not change the number of $\mathrm{KCl}$-activated neurospheres ( $n=4$ experiments, paired $t$ test). $\boldsymbol{B}$, Experimental design to examine the effects of pretreatment with $100 \mu \mathrm{m} \mathrm{NE}$ on NE- and KCl-responsive precursors. C, Pretreatment with $100 \mu \mathrm{m} \mathrm{NE}$ selectively reduced the number of NE- but not KCl-activated neurospheres ( $n=4$ experiments, unpaired $t$ test). $\boldsymbol{D}$, Culturing hippocampal cells in the presence of DA and NE led to no further increase in neurosphere numbers compared with either treatment alone ( $n=5$ experiments). $\boldsymbol{E}$, Combined treatment of DA and KCl resulted in a significant increase in the number of neurospheres compared with that obtained in DA or KCl alone $(n=6$ experiments, unpaired $t$ test). $\boldsymbol{F}$, Pretreatment with $100 \mu \mathrm{m} \mathrm{DA}$ led to a selective reduction in the number of NE-activated but not KCl-activated neurospheres ( $n=5$ experiments, unpaired $t$ test). Values are represented as the mean \pm SEM: ${ }^{*} p<0.05,{ }^{* *} p<0.01$.

$\mathrm{NE}$ - and KCl-responsive quiescent precursor cells are differentially distributed along the septotemporal axis of the hippocampus

Given the mounting evidence suggesting differences in gene expression, connectivity pattern, and function between septal and temporal regions of the hippocampus (Bannerman et al., 2004; Fanselow and Dong, 2010; Kheirbek et al., 2013), we next assessed where the NE- and $\mathrm{KCl}$-responsive quiescent precursors reside along the septotemporal (rostrocaudal) axis of the hippocampus.

$\leftarrow$

(Figure legend continued.) either treatment alone. ( $n=3$ independent experiments for Hes5-GFP and $n=4$ independent experiments for Nestin-GFP; unpaired $t$ test). $F$, Quantification by FACS shows a similar number of Nestin-GFP ${ }^{+} /$EGFR $^{+}$cells from the whole hippocampus $(n=6)$ compared with those present in the dentate gyrus $(n=4)$. G, Table depicting the neurosphere-forming frequency of Hes5-GFP ${ }^{+} /$EGFR $^{+}$cells $(n=3$ independent experiments) and Nestin-GFP ${ }^{+} /$EGFR $^{+}$cells ( $n=4$ independent experiments) plated at clonal density in control (EGF and bFGF), NE, $\mathrm{KCl}$, and $\mathrm{NE}$ and $\mathrm{KCl}$ conditions. Note that nearly all Hes5-GFP ${ }^{+} /$EGFR $^{+}$cells (one neurosphere for every $1.3 \pm 0.4$ cells) formed neurospheres in $\mathrm{NE}$ and $\mathrm{KCl}$, whereas there was only one neurosphere for every 8.6 cells in the control condition. $\boldsymbol{H}, \boldsymbol{I}$, Neurospheres obtained from the Hes5-GFP ${ }^{+} /$EGFR $^{+}(\boldsymbol{H})$ and Nestin-GFP ${ }^{+} /$EGFR $^{+}(\boldsymbol{I})$ fractions as a percentage of the neurospheres obtained from the total GFP ${ }^{+}$population in each of the treatments. J-L, Confocal images showing labeling for Nestin-GFP (green), EGFR (red), and DAPI (blue). GFP and EGFR are colocalized in the RGL $(\boldsymbol{J})$ and non-RGL $(\boldsymbol{L})$ cells in the dentate gyrus. $\boldsymbol{K}$, An orthogonal view of a single $z$-plane showing Nestin-GFP ${ }^{+} /$EGFR $^{+}$colabeled cell along the $x$-axis (bottom) and $y$-axis (right). M, Quantification of the percentage of Nestin$\mathrm{GFP}^{+} / \mathrm{EGFR}^{+}$cells having RGL or non-RGL morphology $(n=10$ sections from two mice; unpaired $t$ test). All values are represented as the mean \pm SEM: ${ }^{*} p<0.05,{ }^{* *} p<0.01$.
Each hippocampus was divided into three equal parts along this axis (septal, middle, and temporal), and the responsiveness of precursor cells residing in each of these subregions to $\mathrm{NE}, \mathrm{KCl}$, and $\mathrm{NE}$ and $\mathrm{KCl}$ was examined (Fig. 4A). A similar number of live cells was obtained from each of these three regions from four hippocampi (septal, $45.1 \pm 1.6 \times 10^{4}$ cells; middle, $47.9 \pm 3.2 \times$ $10^{4}$ cells; temporal, $44.8 \pm 2.4 \times 10^{4}$ cells; $n=3$ experiments). $\mathrm{NE}$ - and $\mathrm{KCl}$-activated neurospheres were obtained from all three regions of the hippocampus; however, a significant increase in the number of neurospheres obtained in the NE and $\mathrm{KCl}$ treatment group was observed only in the middle and temporal regions (Fig. $4 A$ ). The proportion of $\mathrm{NE}$ - but not $\mathrm{KCl}$-activated neurospheres was also significantly reduced between the septal and the temporal regions of the hippocampus, and the temporal region harbored significantly more $\mathrm{KCl}$ - than $\mathrm{NE}$-responsive precursor cells (Fig. $4 B$ ). These results indicate that the anatomical distribution of the quiescent precursor cells that are activated by different stimuli is not uniform along the septotemporal axis of the adult hippocampus.

GABA and corticosterone differentially regulate $\mathrm{NE}$ - and $\mathrm{KCl}$ responsive precursor cells

The results so far have demonstrated that at least two subpopulations of quiescent precursors that are phenotypically similar but are activated by different neurogenic stimuli reside in a nonuniform fashion along the septotemporal axis of the hippocampus. Given that the proliferation of hippocampal precursors is regu- 
A
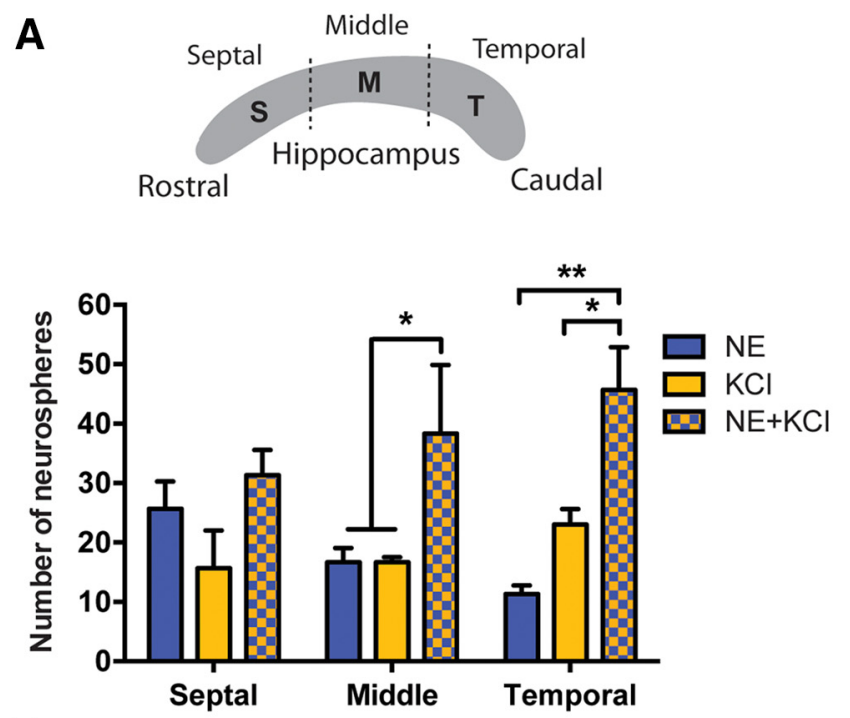

B

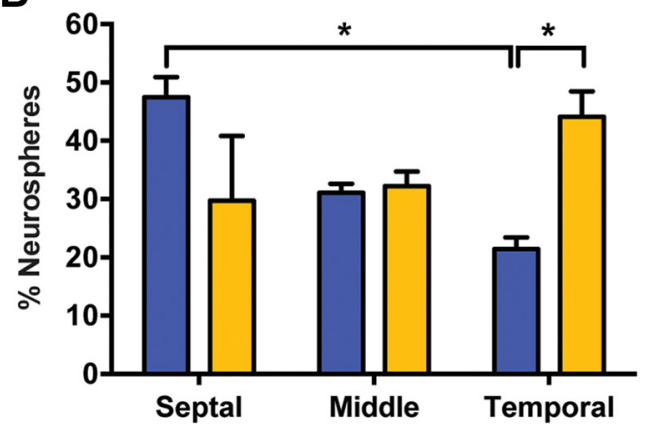

Figure 4. Distribution of NE- and $\mathrm{KCl}$-responsive precursor cells along the septotemporal axis of the hippocampus. $A$, A schematic representing an equal division of the isolated hippocampus into septal $(S)$, middle $(M)$, and temporal $(T)$ regions, and the total number of neurospheres generated from these regions in each of the conditions. Note that a significant increase in the number of neurospheres obtained in NE and $\mathrm{KCl}$ was observed from the middle and temporal regions but not from the septal region of the hippocampus when compared with either treatment alone ( $n=3$ experiments, two-way ANOVA for treatments, $F_{(2,4)}=10.49$, $p<0.05$ ). $\boldsymbol{B}$, Quantification of the proportion of the total NE- or $\mathrm{KCl}$-activated neurospheres across the septal, middle, and temporal regions of the hippocampus revealed a significantly higher proportion of NE-activated neurospheres from the septal versus the temporal hippocampus (two-way ANOVA: $F_{(2,12)}=7.4, p<0.01$ ). Notably, the temporal hippocampus produced significantly more $\mathrm{KCl}$-activated than $\mathrm{NE}$-activated neurospheres. Values are represented as the mean \pm SEM: ${ }^{*} p<0.05,{ }^{* *} p<0.01$.

lated by numerous factors, we next investigated whether neurogenic modulators such as GABA and stress would affect the activity of the two quiescent subpopulations equally or selectively. A recent report (Song et al., 2012) has demonstrated that GABA tonically inhibits the activation of only a proportion of $\mathrm{Nestin}^{+}$quiescent RGL stem cells in the adult hippocampus. We therefore treated hippocampal cells with $\mathrm{NE}$ or $\mathrm{KCl}$ in the absence or presence of GABA. Our results revealed a significant and selective reduction in the number of NE-responsive neurospheres in the presence of $50 \mu \mathrm{M}$ GABA, whereas the total number of $\mathrm{KCl}$-activated neurospheres remained unchanged (Fig. $5 A)$. A significant reduction in stem cell-derived large $(>200 \mu \mathrm{m}$ in diameter) neurospheres was also observed in response to $\mathrm{NE}$ but not $\mathrm{KCl}$ in the presence of GABA (Fig. 5B). These data demonstrate that GABA selectively inhibits activation of the NEresponsive but not the $\mathrm{KCl}$-responsive quiescent precursor cells.

As our earlier results found that the temporal hippocampus, a region shown to be more vulnerable to stress, has significantly more KCl- than NE-responsive quiescent precursors, we hypothesized that stress may selectively affect the activity of $\mathrm{KCl}-$ responsive precursor cells. Given that an elevation in the level of corticosterone has been shown to be a robust biological indicator of both acute and chronic stress (Gould et al., 1998; McEwen, 1999), we examined the effect of exogenous corticosterone in regulating the activity of $\mathrm{NE}$ - versus $\mathrm{KCl}$-responsive precursor cells. Short-term treatment of adult hippocampal cells with 10 $\mu \mathrm{M}$ corticosterone in the neurosphere assay did not alter the total number of neurospheres obtained in NE but marginally reduced the number of $\mathrm{KCl}$-activated neurospheres compared with the untreated control, although this result was not significant (Fig. $5 C ; p=0.31$ ). Interestingly, corticosterone treatment led to a selective and significant reduction in the proportion of $\mathrm{KCl}$ activated stem cell-derived large neurospheres (Fig. 5D), which have previously been shown to constitute $<10 \%$ of the total neurospheres (Walker et al., 2008), suggesting that corticosterone may affect the activation and/or proliferation of $\mathrm{KCl}$-responsive stem cells. We also sought to determine whether chronic corticosterone treatment in vivo would selectively affect the activation of $\mathrm{KCl}$-responsive precursors. Wild-type mice were treated daily with a single injection of $40 \mathrm{mg} / \mathrm{kg}$ corticosterone or vehicle for $7 \mathrm{~d}$, after which their brains were removed, and hippocampal cells from each mouse were plated in control medium containing mitogens (EGF and bFGF) or treated with either $\mathrm{NE}$ or $\mathrm{KCl}$ (Fig. $5 E)$. As expected, treatment with $\mathrm{NE}$ or $\mathrm{KCl}$ resulted in a more than twofold increase in the number of neurospheres obtained from vehicle-treated mice (Fig. $5 F$ ). However, a significant reduction in the number of KCl-activated but not NE-activated neurospheres was observed from the mice treated with corticosterone, suggesting that corticosterone selectively reduces the activation of $\mathrm{KCl}$-responsive precursors (Fig. $5 \mathrm{~F}$ ).

\section{Gene expression analysis of the progeny derived from NE-} and $\mathrm{KCl}$-responsive quiescent precursor cells reveals distinct molecular signatures

Finally, to examine whether $\mathrm{NE}$ - and $\mathrm{KCl}$-activated quiescent precursor cells generate progeny with similar or different molecular profiles, we conducted whole-transcriptome profiling on large neurospheres using next-generation sequencing (Fig. 6A). Sequencing of polyA ${ }^{+}$-enriched cDNA from $\mathrm{KCl}$ - and NEderived neurospheres measuring $>200 \mu \mathrm{m}$ in diameter generated a total of 406 and 301 million reads, respectively, with a mapping efficiency of $>80 \%$ (data not shown). After aligning the RNA sequencing reads to the reference genome, FPKM values were used to measure the gene abundance. Of the total 23,284 genes in the mouse reference (mm10), 13,335 (57.27\%) were detected as expressed genes (FPKM values $>0.5$ ) in at least one of the biological replicates, with 12,812 genes expressed in $\mathrm{KCl}$ derived neurospheres and 13,150 genes expressed in NE-derived neurospheres. Expression analysis using three independent software tools, Cufflinks-Cuffdiff, DESeq, and edgeR, revealed a total of 433 genes that were differentially expressed between NE- and $\mathrm{KCl}$-derived large neurospheres (Fig. 6B). Of these, 301 genes were upregulated, whereas 132 genes were downregulated in NEcompared with $\mathrm{KCl}$-activated large neurospheres. Importantly, cluster analysis of the 433 differentially expressed genes showed high reproducibility across biological replicates (Fig. 6C). We further validated differential expression of these 433 genes using microarrays as an independent transcriptome platform. Comparison of the microarray and RNA sequencing data revealed that 420 of 433 differentially expressed genes were also present in the microarray, with 393 (267 upregulated and 126 downregulated) 
showing consistent differential expression between the two platforms (Fig. 6D). The validation rate of $93.57 \%$ from the microarray analysis of differentially expressed genes further supports our conclusion that the progeny generated by activating NE-responsive versus $\mathrm{KCl}$ responsive precursors is molecularly different. GO enrichment analysis was applied to the differentially expressed genes to identify the pathways and cellular processes that showed significant enrichment in NE-derived versus $\mathrm{KCl}$-derived neurospheres. Specifically, we focused on GO classes associated with neuron development and function that showed significant enrichment (Fig. 6E), which revealed several neurotransmitter receptors, ion channels, and synaptic proteins that were differentially expressed (Fig. $6 F$ ). We further probed our differential gene dataset with that reported in a previous study (Bracko et al., 2012) in which the transcriptomes of purified populations of Sox $2^{+}$neural precursor cells and doublecortin (DCX)-positive immature neuronal cells in the adult hippocampus were compared. Among 433 differentially expressed genes, a number of genes were highly expressed (top 30\%) in $\mathrm{DCX}^{+}$cells. In particular, this analysis showed that transcripts for the neurotransmitter receptor Gabbr1, enriched in NE-activated neurospheres, and Gria4, enriched in $\mathrm{KCl}$-derived progeny, were both expressed and enriched in DCX-positive immature neurons, suggesting that the activation of NE-responsive versus KCl-responsive precursors generates neurons that potentially have different molecular characteristics.

\section{Discussion}

In this study, we have identified and purified to homogeneity almost the entire population of neurosphere-forming precursors from the adult hippocampus. Our findings reveal that within the Hes5-

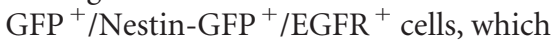
represent a near-pure precursor cell population, there exist two subpopulations of quiescent precursors, one of which that is activated by NE and one that is responsive to $\mathrm{KCl}$. Furthermore, analysis of their anatomical localization shows that the NEand $\mathrm{KCl}$-responsive quiescent precursor subpopulations are not only differentially distributed along the septotemporal axis of the adult hippocampus but are also differentially regulated by neurogenic modulators such as GABA and corticosterone.

Although recent studies have focused on understanding the mechanisms that maintain or activate a large population of quiescent precursor cells residing in the adult hippocampus (Walker

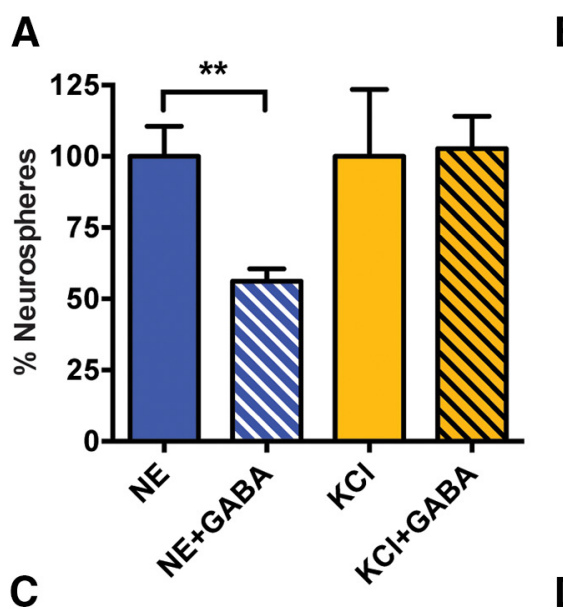

B

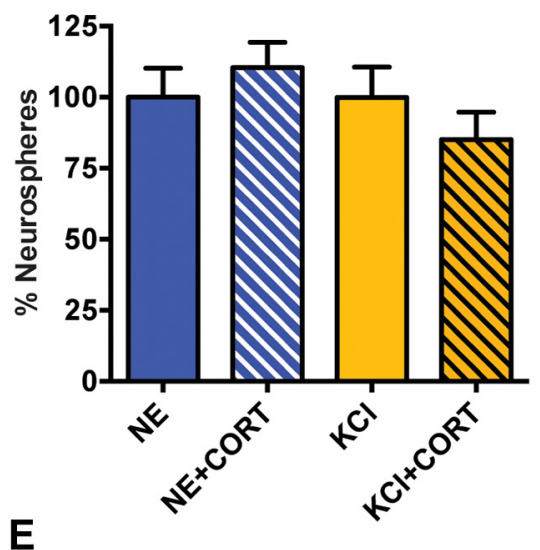

D
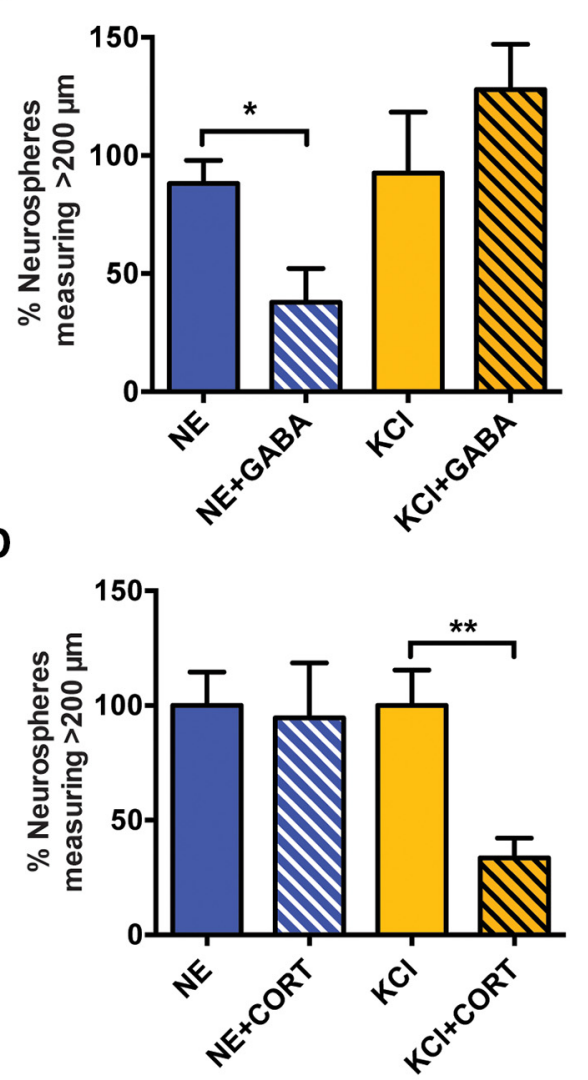

$\mathbf{F}$

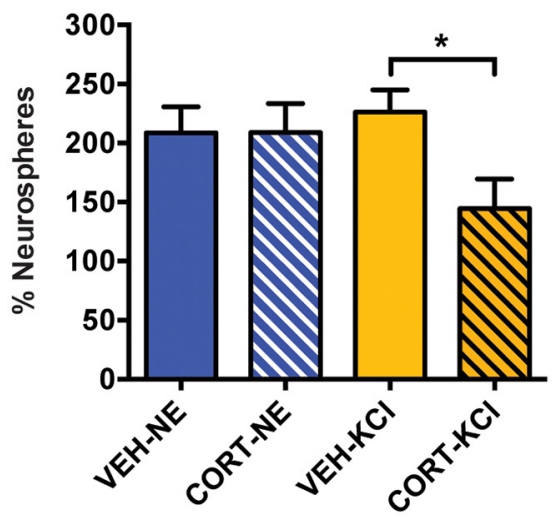

Figure 5. GABA and corticosterone selectively affect the activity of NE- and KCl-responsive precursor cells. $A$, Relative number of neurospheres obtained in the NE and $\mathrm{KCl}$ treatment groups in the absence or presence of GABA $(50 \mu \mathrm{m})$. Note the selective reduction in the NE- but not $\mathrm{KCl}$-activated neurospheres in the presence of GABA ( $n=4$ experiments; unpaired $t$ test). $\boldsymbol{B}$, Distribution of neurospheres based on their size revealed a significant decrease in NE-derived neurospheres across all groups in response to both 50 and $100 \mu \mathrm{m} \mathrm{GABA}$ (unpaired $t$ test). No change in $\mathrm{KCl}$-activated neurospheres was noted in the presence of GABA. C, The relative number of NE- and $\mathrm{KCl}$-activated neurospheres remained unchanged in the presence of $10 \mu \mathrm{m}$ corticosterone (CORT; unpaired $t$ test). D, Distribution of neurospheres based on their size shows a significant reduction in the neurospheres measuring 100-200 $\mu \mathrm{m}$ and $>200 \mu \mathrm{m}$ in $\mathrm{KCl}$ and CORT compared with $\mathrm{KCl}$ alone. No such reduction in neurosphere size was observed in NE and CORT when compared with NE alone ( $n=8$ experiments, unpaired $t$ test). $\boldsymbol{E}$, Experimental outline of the in vivo corticosterone treatment. $\boldsymbol{F}$, The relative number of $\mathrm{KCl}$-activated neurospheres was reduced following the $7 \mathrm{~d}$ treatment with corticosterone in vivo (unpaired $t$ test). Note that the number of NE-activated neurospheres was similar between vehicle-treated mice $(n=5)$ and corticosterone-treated mice $(n=8)$. Data are represented as the mean \pm SEM: ${ }^{*} p<0.05,{ }^{* *} p<0.01$.

et al., 2008; Jhaveri et al., 2010; Lugert et al., 2010; Song et al., 2012), none so far has addressed whether different neurogenic stimuli lead to the activation of different subpopulations of these quiescent precursors. Based on an inducible fate-tracking approach, recent studies have proposed the existence of heteroge- 
A

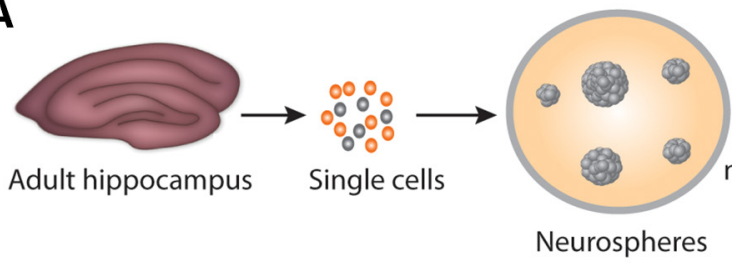

Neurospheres

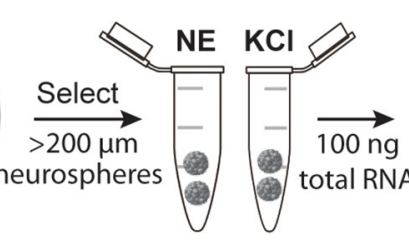

C

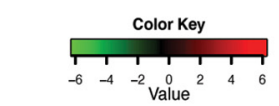

$12_{7}^{5}$

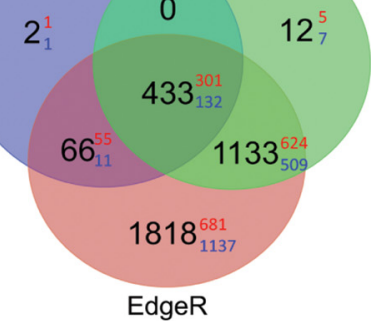

E
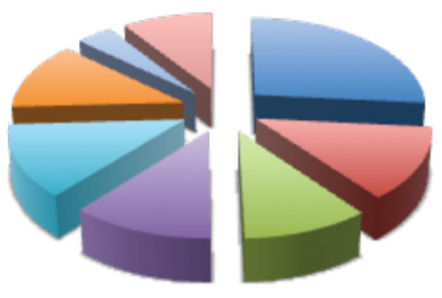

cell adhesion (GO:0007155)

ion homeostasis (GO:0050801)

transmission of nerve impulse (GO:0019226)

neuron projection (GO:0043005)

synapse (GO:0045202)

ion channel activity (GO:0005216)

regulation of action potential in neuron (GO:0019228)

neuron development (GO:0048666)

\section{$\mathbf{F}$}

\begin{tabular}{|c|c|c|c|}
\hline Gene ID & Gene name & $\begin{array}{c}\text { Fold } \\
\text { change }\end{array}$ & $p$ value \\
\hline Chrna4 & cholinergic receptor, nicotinic, alpha polypeptide 4 & -1.00 & 0.0027 \\
\hline Gabbr1 & gamma-aminobutyric acid (GABA-B) receptor, 1 & 1.20 & 0.0018 \\
\hline Gabrb1 & gamma-aminobutyric acid (GABA-A) receptor, subunit beta 1 & 1.60 & 1.96E-05 \\
\hline Gria4 & glutamate receptor, ionotropic, AMPA4 (alpha 4) & -1.63 & 0.0079 \\
\hline Grik3 & glutamate receptor, ionotropic, kainate 3 & 2.74 & $1.35 \mathrm{E}-17$ \\
\hline Cacna1c & calcium channel, voltage-dependent, L type, alpha $1 \mathrm{C}$ subunit & -1.00 & 0.0379 \\
\hline Kcna6 & potassium voltage-gated channel, shaker-related, subfamily, member 6 & 0.99 & $2.81 \mathrm{E}-05$ \\
\hline Kone1I & potassium voltage-gated channel, Isk-related family, member 1-like & 2.44 & 4.60E-06 \\
\hline Kcnk3 & potassium channel, subfamily $\mathrm{K}$, member 3 & 1.26 & 4.94E-08 \\
\hline Kcnn2 & potassium intermediate/small conductance calcium-activated channel, subfamily $\mathrm{N}$ & 1.38 & 4.27E-07 \\
\hline Ryr3 & ryanodine receptor 3 & -1.23 & 4.12E-09 \\
\hline S100a1 & S100 calcium binding protein $\mathrm{A} 1$ & 1.41 & $2.83 \mathrm{E}-06$ \\
\hline Slc4a2 & solute carrier family 4 (anion exchanger), member 2 & -1.37 & 4.33E-11 \\
\hline Slc7a8 & solute carrier family 7 (cationic amino acid transporter), member 8 & 2.62 & $2.25 \mathrm{E}-09$ \\
\hline SIc22a4 & solute carrier family 22 (organic cation transporter), member 4 & 1.83 & $2.70 \mathrm{E}-08$ \\
\hline Slc38a2 & solute carrier family 38, member 2 & -0.87 & $2.30 \mathrm{E}-05$ \\
\hline Synpo2 & synaptopodin 2 & 2.94 & 0.00083 \\
\hline Syt15 & synaptotagmin XV & 3.23 & $1.75 \mathrm{E}-14$ \\
\hline Syt4 & synaptotagmin IV & 1.67 & $3.59 \mathrm{E}-05$ \\
\hline
\end{tabular}

Figure 6. Transcriptome analysis of the progeny derived from NE- versus KCl-responsive precursor cells by deep sequencing. $\boldsymbol{A}$, Experimental plan showing the generation of neurospheres from NE- and KCl-responsive hippocampal precursor cells. RNA was isolated only from large neurospheres ( $>200 \mu \mathrm{m}$ in diameter) obtained in each of the treatments, and the samples were sequenced using a HiSeq 2000 sequencing system. $\boldsymbol{B}$, Venn diagram showing the number of differentially expressed genes identified using Cuffdiff, DESeq, and edgeR between the progeny of $\mathrm{NE}$ - and $\mathrm{KCl}$-responsive precursor cells. Black digits indicate the total number of differentially expressed genes, with red and blue digits indicating the number of upregulated and downregulated genes, respectively. C, Cluster analysis of 433 genes differentially expressed between NE- and KCl-derived neurospheres demonstrate high reproducibility between samples ( $n=4$ biological replicates). The heatmap shows the relative NE/KCl expression values of 433 genes. $D$, Differentially expressed genes obtained from RNA sequencing were further validated using microarray analysis. Note the consistency in differential expression obtained between two transcriptome platforms. $E$, $G 0$ analysis of differentially regulated genes with putative neuronal functions. All classes shown are significantly enriched in their respective categories $(p<0.01)$. $\boldsymbol{F}$, Genes encoding neurotransmitter receptors, ion channels and synaptic proteins that are differentially expressed between the progeny of NE- and KCl-activated precursor cells. A positive fold change denotes higher expression in response to $\mathrm{NE}$ than to $\mathrm{KCl}$. 
neity among hippocampal precursor cells (Bonaguidi et al., 2011; DeCarolis et al., 2013). However, failure to unequivocally identify and isolate true hippocampal stem and precursor cells, together with differences in labeling efficiency between Cre driver lines (DeCarolis et al., 2013), differences in the lineage potential observed among the multiple Nestin-Cre ${ }^{\text {ERT2 }}$ lines generated to date (Bonaguidi et al., 2011; Dranovsky et al., 2011; Encinas et al., 2011), and limitations in the detection sensitivity of fate mapping (Sun et al., 2014), have made the interpretation of these studies difficult. In particular, a major limitation of the genetically defined lineage studies has been the inability to provide any direct insights into the presence of different subpopulations of quiescent precursor cells that differ in their responsiveness to different neurogenic stimuli. The neurosphere assay has emerged as a powerful clonal readout for quantifying stem and precursor cell activity in the brain (Reynolds et al., 1992). The cell-sorting protocol developed in this study to purify the neurosphere-forming hippocampal precursors has allowed the first interrogation of the presence of quiescent subpopulations of precursors that are activated by different stimuli.

A somewhat surprising finding was that a large proportion of Hes5-GFP ${ }^{+} /$Nestin-GFP $^{+} /$EGFR $^{+}$cells did not form neurospheres in the presence of mitogens unless they were also treated with either $\mathrm{NE}$ or $\mathrm{KCl}$, suggesting that the expression of EGFR alone is not sufficient to distinguish between active and quiescent hippocampal precursor cells. This is in contrast to a recent study by Codega et al. (2014), which reported that all active precursors in the SVZ are EGFR ${ }^{+}$and form neurospheres in the presence of mitogens. Quiescent precursors in the SVZ, on the other hand, are $\mathrm{EGFR}^{-}$and very rarely form neurospheres. As we also did not find any neurosphere-forming cells in the Hes5- $\mathrm{GFP}^{-}$or Nestin$\mathrm{GFP}^{-} / \mathrm{EGFR}^{-}$fractions (data not shown), this suggests that the phenotypic identity of non-neurosphere-forming quiescent precursor cells may be similar in the adult SVZ and hippocampus. Given that EGFR ${ }^{+}$cells in the hippocampus comprise both active and quiescent precursor cells, this leads us to speculate that $\mathrm{EGFR}^{+}$quiescent precursors may be in a different functional state compared with $\mathrm{EGFR}^{-}$quiescent precursors. As we have previously demonstrated that $\beta 3$-adrenergic receptors, which are part of the G-protein-coupled receptor (GPCR) family, are expressed on NE-responsive precursors (Jhaveri et al., 2010), it is likely that GPCR-mediated transactivation of EGFR drives the activation and proliferation of these $\mathrm{EGFR}^{+}$cells (for review, see George et al., 2013). Similarly, KCl, acting via L-type calcium channels, may also lead to transactivation of EGFR signaling (Zwick et al., 1997). Such a mechanism would ensure the rapid cell cycle entry of activatable $\left(\mathrm{EGFR}^{+}\right)$quiescent precursor cells upon neurogenic stimulation as well as the preservation of the non-activatable $\left(\mathrm{EGFR}^{-}\right)$quiescent precursor pool. A similar mechanism has recently been proposed to occur in quiescent populations of muscle stem cells, which transition from $G_{o}$ to $\mathrm{G}_{\text {alert }}$ as an adaptive response to injury and stress (Rodgers et al., 2014).

An important question to consider is why multiple quiescent precursor cell populations exist in the adult hippocampus, given that they primarily generate dentate granule neurons. A growing body of evidence suggests that anatomical, molecular, and functional differences exist along the dorsoventral axis of the hippocampus (Fanselow and Dong, 2010). Emerging findings have implicated the septal or dorsal hippocampus in the regulation of spatial learning, whereas the temporal or ventral hippocampus preferentially regulates anxiety/mood-related behaviors (Kheir- bek et al., 2013). Furthermore, differences in the maturation rate of adult-born neurons have been observed along the septotemporal axis, with temporally located newborn neurons maturing at a slower rate than their septal counterparts (Piatti et al., 2011). Our findings that NE- and $\mathrm{KCl}$-responsive precursors are differentially distributed along the septotemporal axis, with a greater proportion of the NE-responsive population being located in the septal region and a higher number of $\mathrm{KCl}$-responsive than NEresponsive precursors residing in the temporal region, suggest that discrete precursor subpopulations may underlie the differences in the functional properties of newborn neurons in these regions, thereby adding another layer of complexity to our current understanding of adult neurogenesis along this axis. In support of this possibility, our RNA sequencing and microarray analyses have found that a number of genes involved in synaptic transmission, including neurotransmitter receptors, ion channels, and synaptic proteins, are differentially expressed between the progeny of NE- and $\mathrm{KCl}$-responsive quiescent precursor cells, suggesting that new neurons generated by activating distinct precursor subpopulations may have different functional properties. However, the possibility that some of the differences in the gene expression observed between the progeny of NE- and $\mathrm{KCl}$ responsive precursors reflect the effect of treatment rather than the intrinsic properties of precursor subpopulation cannot currently be excluded.

Fate-mapping and transplantation studies have demonstrated that adult precursor cells along the dorsoventral axis of the SVZ are functionally heterogeneous and maintain their regional identity by producing region-specific neuronal populations both in vitro and in vivo (Kelsch et al., 2007; Merkle et al., 2007). However, whether new neurons arising from different subpopulations of hippocampal precursors also maintain such a regional specificity remains an important question for future studies. Interestingly, a recent report (Brunner et al., 2014) has proposed the presence of at least two SGZ populations of adult-born neurons with different intrinsic excitability properties that are largely independent of their cellular age or maturation stage. Furthermore, as we have shown that GABA selectively attenuates the activation of NE-responsive precursor cells, whereas exogenous corticosterone treatment specifically affects the $\mathrm{KCl}$-responsive population, this prompts us to speculate that neurogenic modulators may selectively alter the proliferative capacity of a subpopulation of quiescent precursor cells, thereby leading to region-specific regulation in new neuron production.

Increasing evidence points toward stem cell heterogeneity as a common occurrence across adult somatic stem cells, particularly in the hematopoietic system where substantial progress has been made in understanding the functional contribution of phenotypically separable subsets of stem cells in generating lymphoid versus myeloid lineages (Schroeder, 2010; Lu et al., 2011). The ability to purify hippocampal precursor cells combined with single-cell genomics may provide deeper insights into their molecular properties and will provide an unbiased means to interrogate distinct subpopulations of quiescent cells. For example, it will help to uncover whether precursors differ in their levels of $\beta 3$-adrenergic receptors, which may underlie differences in their responsiveness to $\mathrm{NE}$ or $\mathrm{KCl}$. The current study has advanced our understanding of the phenotypic identity of quiescent precursors and their responsiveness to different neurogenic stimuli; however, determining the functional outcomes of activating these select subpopulations in vivo remains a challenge. Ultimately, understanding the functional contribution of new neurons generated by activating these distinct subpopulations will be essential to guide future regen- 
erative strategies for the treatment of learning- and mood-related disorders.

\section{Notes}

Supplemental material, including Supplemental Tables 1, 2, and 3, for this article is available at https://github.com/Qiongyi/supplemental_files. This material has not been peer reviewed.

\section{References}

Anders S, Huber W (2010) Differential expression analysis for sequence count data. Genome Biol 11:R106. CrossRef Medline

Bannerman DM, Rawlins JN, McHugh SB, Deacon RM, Yee BK, Bast T, Zhang WN, Pothuizen HH, Feldon J (2004) Regional dissociations within the hippocampus-memory and anxiety. Neurosci Biobehav Rev 28:273-283. CrossRef Medline

Bonaguidi MA, Wheeler MA, Shapiro JS, Stadel RP, Sun GJ, Ming GL, Song H (2011) In vivo clonal analysis reveals self-renewing and multipotent adult neural stem cell characteristics. Cell 145:1142-1155. CrossRef Medline

Bracko O, Singer T, Aigner S, Knobloch M, Winner B, Ray J, Clemenson GD Jr, Suh H, Couillard-Despres S, Aigner L, Gage FH, Jessberger S (2012) Gene expression profiling of neural stem cells and their neuronal progeny reveals IGF2 as a regulator of adult hippocampal neurogenesis. J Neurosci 32:3376-3387. CrossRef Medline

Brummelte S, Galea LA (2010) Chronic high corticosterone reduces neurogenesis in the dentate gyrus of adult male and female rats. Neuroscience 168:680-690. CrossRef Medline

Brunner J, Neubrandt M, Van-Weert S, Andrási T, Kleine Borgmann FB, Jessberger S, Szabadics J (2014) Adult-born granule cells mature through two functionally distinct states. eLife 3:e03104. CrossRef

Codega P, Silva-Vargas V, Paul A, Maldonado-Soto AR, Deleo AM, Pastrana E, Doetsch F (2014) Prospective identification and purification of quiescent adult neural stem cells from their in vivo niche. Neuron 82:545559. CrossRef Medline

DeCarolis NA, Mechanic M, Petrik D, Carlton A, Ables JL, Malhotra S, Bachoo R, Götz M, Lagace DC, Eisch AJ (2013) In vivo contribution of nestin- and GLAST-lineage cells to adult hippocampal neurogenesis. Hippocampus 23:708-719. CrossRef Medline

Deng W, Aimone JB, Gage FH (2010) New neurons and new memories: how does adult hippocampal neurogenesis affect learning and memory? Nat Rev Neurosci 11:339-350. CrossRef Medline

Dranovsky A, Picchini AM, Moadel T, Sisti AC, Yamada A, Kimura S, Leonardo ED, Hen R (2011) Experience dictates stem cell fate in the adult hippocampus. Neuron 70:908-923. CrossRef Medline

Encinas JM, Michurina TV, Peunova N, Park JH, Tordo J, Peterson DA, Fishell G, Koulakov A, Enikolopov G (2011) Division-coupled astrocytic differentiation and age-related depletion of neural stem cells in the adult hippocampus. Cell Stem Cell 8:566-579. CrossRef Medline

Fanselow MS, Dong HW (2010) Are the dorsal and ventral hippocampus functionally distinct structures? Neuron 65:7-19. CrossRef Medline

Gao X, Enikolopov G, Chen J (2008) Direct isolation of neural stem cells in the adult hippocampus after traumatic brain injury. J Neurotrauma 25: 985-995. CrossRef Medline

George AJ, Hannan RD, Thomas WG (2013) Unravelling the molecular complexity of GPCR-mediated EGFR transactivation using functional genomics approaches. FEBS J 280:5258-5268. CrossRef Medline

Gould E, Tanapat P, McEwen BS, Flügge G, Fuchs E (1998) Proliferation of granule cell precursors in the dentate gyrus of adult monkeys is diminished by stress. Proc Natl Acad Sci U S A 95:3168-3171. CrossRef Medline

Huang da W, Sherman BT, Lempicki RA (2009) Systematic and integrative analysis of large gene lists using DAVID bioinformatics resources. Nat Protoc 4:44-57. CrossRef Medline

Huang GJ, Herbert J (2006) Stimulation of neurogenesis in the hippocampus of the adult rat by fluoxetine requires rhythmic change in corticosterone. Biol Psychiatry 59:619-624. CrossRef Medline

Jhaveri DJ, Mackay EW, Hamlin AS, Marathe SV, Nandam LS, Vaidya VA, Bartlett PF (2010) Norepinephrine directly activates adult hippocampal precursors via $\beta 3$-adrenergic receptors. J Neurosci 30:2795-2806. CrossRef Medline

Jhaveri DJ, Taylor CJ, Bartlett PF (2012) Activation of different neural precursor populations in the adult hippocampus: does this lead to new neu- rons with discrete functions? Dev Neurobiol 72:1044-1058. CrossRef Medline

Johnson SA, Fournier NM, Kalynchuk LE (2006) Effect of different doses of corticosterone on depression-like behavior and HPA axis responses to a novel stressor. Behav Brain Res 168:280-288. CrossRef Medline

Kameda M, Taylor CJ, Walker TL, Black DM, Abraham WC, Bartlett PF (2012) Activation of latent precursors in the hippocampus is dependent on long-term potentiation. Transl Psychiatry 2:e72. CrossRef Medline

Kelsch W, Mosley CP, Lin CW, Lois C (2007) Distinct mammalian precursors are committed to generate neurons with defined dendritic projection patterns. PLoS Biol 5:e300. CrossRef Medline

Kheirbek MA, Drew LJ, Burghardt NS, Costantini DO, Tannenholz L, Ahmari SE, Zeng H, Fenton AA, Hen R (2013) Differential control of learning and anxiety along the dorsoventral axis of the dentate gyrus. Neuron 77:955-968. CrossRef Medline

Lu R, Neff NF, Quake SR, Weissman IL (2011) Tracking single hematopoietic stem cells in vivo using high-throughput sequencing in conjunction with viral genetic barcoding. Nat Biotechnol 29:928-933. CrossRef Medline

Lugert S, Basak O, Knuckles P, Haussler U, Fabel K, Götz M, Haas CA, Kempermann G, Taylor V, Giachino C (2010) Quiescent and active hippocampal neural stem cells with distinct morphologies respond selectively to physiological and pathological stimuli and aging. Cell Stem Cell 6:445-456. CrossRef Medline

Lugert S, Vogt M, Tchorz JS, Muller M, Giachino C, Taylor V (2012) Homeostatic neurogenesis in the adult hippocampus does not involve amplification of Ascl1(high) intermediate progenitors. Nat Commun 3:670. CrossRef Medline

McEwen BS (1999) Stress and hippocampal plasticity. Annu Rev Neurosci 22:105-122. CrossRef Medline

Merkle FT, Mirzadeh Z, Alvarez-Buylla A (2007) Mosaic organization of neural stem cells in the adult brain. Science 317:381-384. CrossRef Medline

Ming GL, Song H (2005) Adult neurogenesis in the mammalian central nervous system. Annu Rev Neurosci 28:223-250. CrossRef Medline

Murray F, Smith DW, Hutson PH (2008) Chronic low dose corticosterone exposure decreased hippocampal cell proliferation, volume and induced anxiety and depression like behaviours in mice. Eur J Pharmacol 583:115127. CrossRef Medline

Narayanan RK, Mangelsdorf M, Panwar A, Butler TJ, Noakes PG, Wallace RH (2013) Identification of RNA bound to the TDP-43 ribonucleoprotein complex in the adult mouse brain. Amyotroph Lateral Scler Frontotemporal Degener 14:252-260. CrossRef Medline

Pastrana E, Cheng LC, Doetsch F (2009) Simultaneous prospective purification of adult subventricular zone neural stem cells and their progeny. Proc Natl Acad Sci U S A 106:6387-6392. CrossRef Medline

Piatti VC, Davies-Sala MG, Espósito MS, Mongiat LA, Trinchero MF, Schinder AF (2011) The timing for neuronal maturation in the adult hippocampus is modulated by local network activity. J Neurosci 31:7715-7728. CrossRef Medline

Reynolds BA, Tetzlaff W, Weiss S (1992) A multipotent EGF-responsive striatal embryonic progenitor cell produces neurons and astrocytes. J Neurosci 12:4565-4574. Medline

Robinson MD, McCarthy DJ, Smyth GK (2010) edgeR: a Bioconductor package for differential expression analysis of digital gene expression data. Bioinformatics 26:139-140. CrossRef Medline

Rodgers JT, King KY, Brett JO, Cromie MJ, Charville GW, Maguire KK, Brunson C, Mastey N, Liu L, Tsai CR, Goodell MA, Rando TA (2014) mTORC1 controls the adaptive transition of quiescent stem cells from G0 to G(Alert). Nature 510:393-396. CrossRef Medline

Sahay A, Hen R (2007) Adult hippocampal neurogenesis in depression. Nat Neurosci 10:1110-1115. CrossRef Medline

Santarelli L, Saxe M, Gross C, Surget A, Battaglia F, Dulawa S, Weisstaub N, Lee J, Duman R, Arancio O, Belzung C, Hen R (2003) Requirement of hippocampal neurogenesis for the behavioral effects of antidepressants. Science 301:805-809. CrossRef Medline

Saxe MD, Battaglia F, Wang JW, Malleret G, David DJ, Monckton JE, Garcia AD, Sofroniew MV, Kandel ER, Santarelli L, Hen R, Drew MR (2006) Ablation of hippocampal neurogenesis impairs contextual fear conditioning and synaptic plasticity in the dentate gyrus. Proc Natl Acad Sci U S A 103:17501-17506. CrossRef Medline 
Schroeder T (2010) Hematopoietic stem cell heterogeneity: subtypes, not unpredictable behavior. Cell Stem Cell 6:203-207. CrossRef Medline

Snyder JS, Soumier A, Brewer M, Pickel J, Cameron HA (2011) Adult hippocampal neurogenesis buffers stress responses and depressive behaviour. Nature 476:458-461. CrossRef Medline

Song J, Zhong C, Bonaguidi MA, Sun GJ, Hsu D, Gu Y, Meletis K, Huang ZJ, Ge S, Enikolopov G, Deisseroth K, Luscher B, Christian KM, Ming GL, Song H (2012) Neuronal circuitry mechanism regulating adult quiescent neural stem-cell fate decision. Nature 489:150-154. CrossRef Medline

Sun MY, Yetman MJ, Lee TC, Chen Y, Jankowsky JL (2014) Specificity and efficiency of reporter expression in adult neural progenitors vary substantially among nestin-CreER(T2) lines. J Comp Neurol 522:1191-1208. CrossRef Medline

Trapnell C, Pachter L, Salzberg SL (2009) TopHat: discovering splice junctions with RNA-Seq. Bioinformatics 25:1105-1111. CrossRef Medline

Trapnell C, Williams BA, Pertea G, Mortazavi A, Kwan G, van Baren MJ, Salzberg SL, Wold BJ, Pachter L (2010) Transcript assembly and quantification by RNA-Seq reveals unannotated transcripts and isoform switching during cell differentiation. Nat Biotechnol 28:511-515. CrossRef Medline

Vukovic J, Borlikova GG, Ruitenberg MJ, Robinson GJ, Sullivan RK, Walker TL, Bartlett PF (2013) Immature doublecortin-positive hippocampal neurons are important for learning but not for remembering. J Neurosci 33:6603-6613. CrossRef Medline

Walker TL, White A, Black DM, Wallace RH, Sah P, Bartlett PF (2008) Latent stem and progenitor cells in the hippocampus are activated by neural excitation. J Neurosci 28:5240-5247. CrossRef Medline

Walker TL, Wierick A, Sykes AM, Waldau B, Corbeil D, Carmeliet P, Kempermann G (2013) Prominin-1 allows prospective isolation of neural stem cells from the adult murine hippocampus. J Neurosci 33:3010-3024. CrossRef Medline

Wong EY, Herbert J (2006) Raised circulating corticosterone inhibits neuronal differentiation of progenitor cells in the adult hippocampus. Neuroscience 137:83-92. CrossRef Medline

Yu TS, Dandekar M, Monteggia LM, Parada LF, Kernie SG (2005) Temporally regulated expression of Cre recombinase in neural stem cells. Genesis 41:147-153. CrossRef Medline

Zhang ZH, Jhaveri DJ, Marshall VM, Bauer DC, Edson J, Narayanan RK, Robinson GJ, Lundberg AE, Bartlett PF, Wray NR, Zhao QY (2014) A comparative study of techniques for differential expression analysis on RNA-seq data. PLoS One 9:e103207. CrossRef Medline

Zwick E, Daub H, Aoki N, Yamaguchi-Aoki Y, Tinhofer I, Maly K, Ullrich A (1997) Critical role of calcium- dependent epidermal growth factor receptor transactivation in PC12 cell membrane depolarization and bradykinin signaling. J Biol Chem 272:24767-24770. CrossRef Medline 